\title{
CHITOSAN DRIVES ANTI-INFLAMMATORY MACROPHAGE POLARISATION AND PRO-INFLAMMATORY DENDRITIC CELL STIMULATION
}

\author{
Marta I. Oliveira $^{1}$, Susana G. Santos ${ }^{1}$, Maria J. Oliveira ${ }^{1,2}$, Ana L. Torres ${ }^{1,3}$ and Mário A. Barbosa ${ }^{1,4 *}$ \\ ${ }^{1}$ Instituto de Engenharia Biomédica, Universidade do Porto, Porto, Portugal \\ ${ }^{2}$ Faculdade de Medicina, Universidade do Porto, Porto, Portugal \\ ${ }^{3}$ Faculdade de Engenharia, Universidade do Porto, Porto, Portugal \\ ${ }^{4}$ Instituto Ciências Biomédicas Abel Salazar, Universidade do Porto, Porto, Portugal
}

\begin{abstract}
Macrophages and dendritic cells (DC) share the same precursor and play key roles in immunity. Modulation of their behaviour to achieve an optimal host response towards an implanted device is still a challenge. Here we compare the differentiation process and polarisation of these related cell populations and show that they exhibit different responses to chitosan (Ch), with human monocyte-derived macrophages polarising towards an anti-inflammatory phenotype while their DC counterparts display pro-inflammatory features. Macrophages and DC, whose interactions with biomaterials are frequently analysed using fully differentiated cells, were cultured directly on $\mathrm{Ch}$ films, rather than exposed to the polymer after complete differentiation. Ch was the sole stimulating factor and activated both macrophages and $\mathrm{DC}$, without leading to significant $\mathrm{T}$ cell proliferation. After $10 \mathrm{~d}$ on $\mathrm{Ch}$, macrophages significantly down-regulated expression of pro-inflammatory markers, CD86 and MHCII. Production of pro-inflammatory cytokines, particularly TNF- $\alpha$, decreased with time for cells cultured on $\mathrm{Ch}$, while anti-inflammatory IL-10 and TGF- $\beta 1$, significantly increased. Altogether, these results suggest an M2c polarisation. Also, macrophage matrix metalloproteinase activity was augmented and cell motility was stimulated by Ch. Conversely, DC significantly enhanced CD86 expression, reduced IL-10 secretion and increased TNF- $\alpha$ and IL-1 $\beta$ levels. Our findings indicate that cells with a common precursor may display different responses, when challenged by the same biomaterial. Moreover, they help to further comprehend macrophage/DC interactions with $\mathrm{Ch}$ and the balance between pro- and anti-inflammatory signals associated with implant biomaterials. We propose that an overall pro-inflammatory reaction may hide the expression of anti-inflammatory cytokines, likely relevant for tissue repair/regeneration.
\end{abstract}

Keywords: Macrophage; dendritic cell; chitosan; polarisation; cell activation; immunomodulation; inflammation; immune response.

*Address for correspondence:

Mário Adolfo Barbosa

Instituto de Engenharia Biomédica

Universidade do Porto

Rua do Campo Alegre 823

4150-180-Porto, Portugal

Telephone Number: 351226074981

FAX Number: 351226094567

Email: mbarbosa@ineb.up.pt

\section{Introduction}

Understanding the biological events taking place at implant surfaces is of key relevance for the development of successful and functional biomaterials. A multitude of host cell populations respond to implantation, both at short and long-term, and the inter-communication established will depend on the biomaterial characteristics. Immune cells, in particular macrophages, mediate a great number of responses, ranging from initial inflammation to tissue remodelling and regeneration, through clearance of exogenous agents and production of cytokines and chemokines that activate/deactivate or recruit other surrounding inflammatory or wound healing cells to the injury site (Xia and Triffitt, 2006). Besides their role as inflammatory mediators, these phagocytic cells have also the remarkable characteristic of presenting antigens to $\mathrm{T}$ cells, thereby initiating the mechanisms of adaptive immunity. Depending on the micro-environmental stimuli received, macrophages can display either pro- or antiinflammatory features, performing distinctive functions. Classically or pro-inflammatory-activated macrophages, also designated as M1, can be primed by interferon $\gamma$ (INF $\gamma$ ) and/or lipopolysaccharides (LPS) and have high microbicidal activity, with increased production of proinflammatory cytokines. On the other hand, alternativelyactivated M2 macrophages, primed by interleukin (IL)-4 (IL-4) and IL-13 (M2a subset), immune complexes and LPS (M2b subset), or IL-10 (M2c subset), are associated with an anti-inflammatory profile and are crucial in tissue remodelling after inflammation (Mantovani et al., 2005; Mantovani et al., 2004).

In addition to macrophages, another immune cell type with key functions in immunity is the dendritic cell population. They are specialised in the up-take, processing and presentation of antigens, including implant-associated antigens (Babensee et al., 1998) to T lymphocytes and are considered professional antigen presenting cells (APC) (Banchereau et al., 2000). Similarly to macrophages, dendritic cells (DC) also show some degree of plasticity, depending on the external stimuli. Inflammatory or classical mature DC can be activated by foreign antigens, produce pro-inflammatory cytokines and stimulate T cells, whereas tolerogenic and regulatory DC can be activated by self-antigens or anti-inflammatory molecules, release anti-inflammatory cytokines and induce the expansion of regulatory $\mathrm{T}$ cells, in a striking resemblance with M1 and M2 macrophages (Kou and Babensee, 2011). Despite sharing the same precursor, the myeloid-monocyte haematopoietic cell, as well as significant overlapping 
functions, macrophages and DC display different cell surface expression molecules, particularly upon activation. Furthermore, the innate cytotoxicity of macrophages and their ability to fuse forming foreign body giant cells renders them unique (Kou and Babensee, 2011). As these two cell types bridge innate and adaptive immunity, guiding the host response, understanding their cellular behaviour to a specific material is of foremost importance for effective applicability of devices in a tissue engineering perspective. Moreover, this knowledge is crucial for the development of new biomaterial-based strategies that, through modulation of the macrophage/DC phenotype towards reparative/tolerogenic functions, could enhance tissue regeneration. In this context, a comparative investigation of both human monocyte-derived macrophages and DC differentiation and maturation directly on the same biomaterial was carried out and is presented herein. The natural and biocompatible polymer chitosan $(\mathrm{Ch})$, intensively investigated for a wide range of biomedical applications, such as drug delivery, wound dressings, and tissue engineering strategies (Baldrick, 2010; Dash et al., 2011; Kim et al., 2008; Muzzarelli, 2009; Ueno et al., 2001a), was selected and presented to cells as an ultrathin matrix on which macrophage and DC differentiation took place during 10 or $7 \mathrm{~d}$, respectively. This approach was selected since biomaterial surfaces have been shown to affect macrophage phenotype (Ariganello et al., 2011; Dinnes et al., 2008; Jones et al., 2007), and because Ch, reported as immuno-stimulatory (Mori et al., 1997; Peluso et al., 1994; Porporatto et al., 2003; Ueno et al., 2001b), is frequently presented to already differentiated cells (Mori et al., 2005; Peluso et al., 1994; Porporatto et al., 2003), possibly underestimating its potential to modulate immune cell behaviour during the inflammatory and later repair processes. The host-tissue response to Ch-based implants has been investigated with contradictory results. Some studies have documented $\mathrm{Ch}$ as a material that evokes a minimal foreign body reaction (Azab et al., 2007; Yussof et al., 2011), which would render it suitable for tissue engineering. No evidence of exacerbated inflammatory reaction to the material itself was found for different species and implantation sites, including Ch (degree of acetylation $(\mathrm{DA})=15 \%$ ) implants in the spinal cord of rats, in comparison with Vicryl and Gore-Tex (Kim et al., 2011), intraperitoneal and subcutaneous implantation of a $\mathrm{Ch}(\mathrm{DA}=8 \%$ ) scaffold in mice (VandeVord et al., 2002) and subcutaneous implantation in rats of a $\mathrm{Ch}(\mathrm{DA}=$ $11 \%$ ) bilayer relative to two commercially available skin substitutes (Yussof et al., 2011). Conversely, others found a pronounced inflammatory response induced by $\mathrm{Ch}$, as in the case of $\mathrm{Ch}(\mathrm{DA}=15 \%)$ injection to the brain in rats (Crompton et al., 2006) and subcutaneous implantation of Ch (DA= $15 \%)$ samples in rats (Peluso et al., 1994). These contradictory data are quite often related to purity, contaminants and differences in the DA of the polymer. In fact, it has been shown that the inflammatory reaction to Ch can be reduced by decreasing its DA (Barbosa et al., 2010; Hidaka et al., 1999; Kim et al., 2011; Tomihata and Ikada, 1997).

In this investigation, macrophages and DC were cultured directly on $\mathrm{Ch}$ films, rather than exposed to the polymer after complete differentiation. Ch was the sole stimulating factor and its role on macrophage polarisation and DC stimulation was studied.

\section{Materials and Methods}

\section{Chitosan films}

High molecular weight (Mw) chitosan (France Chitine, Orange, France, degree of N-acetylation of 11-12\%, Mw $324 \pm 27 \times 10^{3}$, endotoxin-free) was hydrated using Milli-Q water, and then dissolved in $0.1 \mathrm{M} \mathrm{HCl}$ under stirring and filtered. Ch was next precipitated with $0.1 \mathrm{M}$ $\mathrm{KOH}$, washed with Milli-Q water, freeze-dried (48 h) and finally milled (IKA, Königswinter, Germany) until a fine powder was obtained. After purification $\mathrm{Ch}$ was dissolved in $0.2 \mathrm{M}$ acetic acid and the solution $(0.5 \%)$ degassed, filtered through $0.2 \mu \mathrm{m}$ pore filters (Millipore, Billerica, MA, USA) and stored at $4{ }^{\circ} \mathrm{C}$ protected from light. As substrate, glass coverslips, previously washed overnight with $65 \%$ nitric acid, washed several times with distilled water and calcinated overnight at $220{ }^{\circ} \mathrm{C}$, were used. $\mathrm{Ch}$ films of $24 \pm 4 \mathrm{~nm}$ thickness (measured by ellipsometry; data not shown) were prepared by spincoating ( 2 min at $9000 \mathrm{rpm}$ ) on these glass coverslips. After spinning, films were neutralised with $0.1 \mathrm{M} \mathrm{NaOH}$ for $5 \mathrm{~min}$, washed twice with MilliQ water and dried for $24 \mathrm{~h}$ at $37{ }^{\circ} \mathrm{C}$. Prior to cell culture, films were sterilised with filtered $70 \%$ ethanol, washed twice with phosphate-buffered saline (PBS, SigmaAldrich Inc., St. Louis, MO, USA) and incubated with complete medium for $1 \mathrm{~h}$ at $37^{\circ} \mathrm{C}$.

\section{Cell culture}

Human primary monocytes were obtained from buffy coats (BC) from healthy blood donors, kindly donated by Instituto Português do Sangue, using the RosetteSep human monocyte enrichment isolation kit (StemCell Technologies SARL, Grenoble, France). Briefly, BC were centrifuged at room temperature for $20 \mathrm{~min}$ at $1200 \mathrm{~g}$ without active brake. The peripheral blood mononuclear cell (PBMC) layer was collected and incubated with RosetteSep human monocyte enrichment isolation kit according to the manufacturer's instructions. The mixture was then diluted at a $1: 1$ ratio with PBS, $2 \%$ foetal bovine serum (FBS, Lonza, Basel, Switzerland) before being layered over Histopaque ${ }^{\circledR}-1077$ (Sigma-Aldrich) and centrifuged as previously. The enriched monocyte layer was collected carefully and washed with PBS. The washes were performed at $700 \mathrm{rpm}$ for $17 \mathrm{~min}$ to ensure platelet removal. Finally, the pellet was resuspended in complete culture medium (CM-RPMI 1640 + Glutamax (Invitrogen, Paisley, UK)) supplemented with $10 \%$ FBS and $1 \%$ penicillin G-streptomycin (Invitrogen). The recovered population routinely contained $>70 \%$ of CD14 positive cells and no other detectable cell population (Fig. 1A). Cells were then counted in a Neubauer chamber using the trypan blue dye (Sigma-Aldrich)-exclusion assay, plated on Ch films or tissue culture polystyrene (TCPS) plates (BD Biosciences, Franklin Lakes, NJ, USA) and cultured in a humidified $37{ }^{\circ} \mathrm{C} / 5 \% \mathrm{CO}_{2}$ incubator for different periods of time. Monocytes were allowed to differentiate 

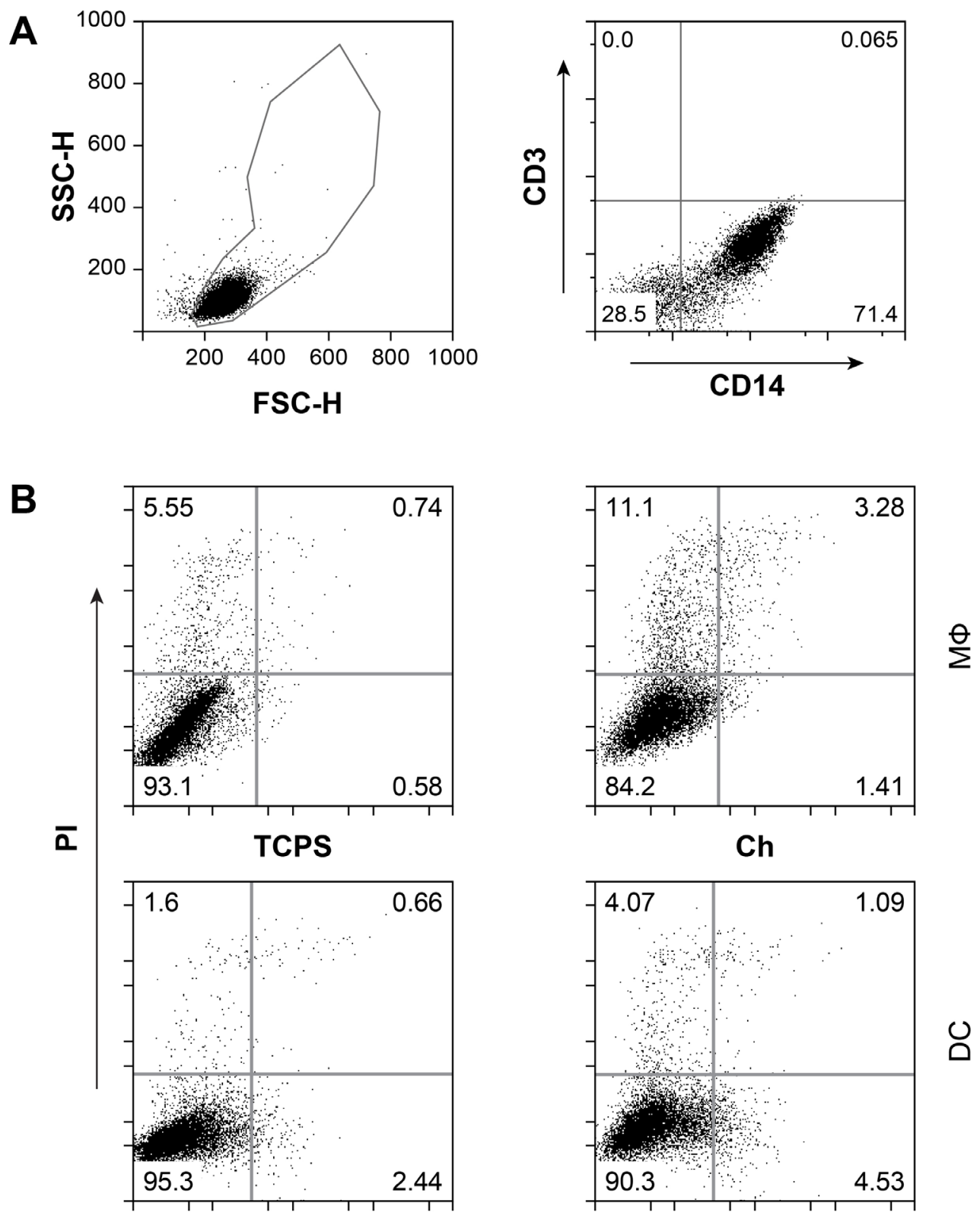

Ch

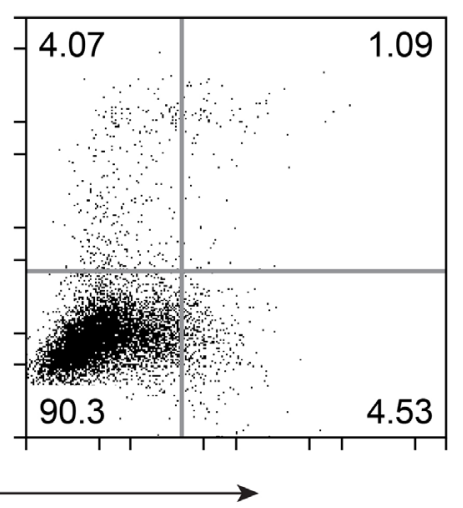

O

\section{Annexin}

Fig. 1. Cell population purity and viability. Cells were obtained from buffy coats and monocyte isolation performed by negative selection using RosetteSep monocyte enrichment kit. (A) Aspect ratio (left panel) and CD3 (T cell marker) and CD14 (monocyte lineage marker) double staining (right panel) of cells immediately after purification. (B) Viability of macrophages (top panels) and DC (bottom panels) was analysed by Annexin/PI staining after 10 or $7 \mathrm{~d}$ of culture, respectively, on TCPS (left panels) and Ch (right panels). MФ, macrophages; DC, dendritic cells; TCPS, tissue culture polystyrene; Ch, chitosan; PI, propidium iodide; FSC, forward scatter; SSC, side scatter.

into macrophages, without addition of cytokines, for 3,7 or $10 \mathrm{~d}$ as commonly performed in macrophagebiomaterial studies (Anderson and Jones, 2007; Jones et al., 2007; Jones et al., 2008). Monocyte-derived DC were differentiated as described previously (Chapuis et al., 1997; Sallusto and Lanzavecchia, 1994). Briefly, monocytes were cultured for $7 \mathrm{~d}$ with IL-4 $(50 \mathrm{ng} / \mathrm{mL})$ and GM-CSF ( $50 \mathrm{ng} / \mathrm{mL}$ ) (both from Immunotools, Friesoythe, Germany) to obtain fully differentiated immature DC. Cell differentiation was assessed by cell surface labelling for lineage markers, CD14 for macrophages or CD1a for DC
(Chapuis et al., 1997; Kou and Babensee, 2011), and flow cytometry. To induce macrophage polarisation into proinflammatory M1 or anti-inflammatory M2c phenotypes, cells cultured on TCPS were treated at day 7 with $10 \mathrm{ng} / \mathrm{mL}$ lipopolysaccharide (LPS) or $10 \mathrm{ng} / \mathrm{mL}$ IL-10, respectively, and left in culture for an additional $3 \mathrm{~d}$. This protocol was adapted from a previously described method (Porcheray et $a l ., 2005)$. To promote DC maturation, cells differentiated on TCPS were treated with $50 \mathrm{ng} / \mathrm{mL}$ LPS for $24 \mathrm{~h}$ (Santos et al., 2008; Verhasselt et al., 1997). Purified T cells were isolated from $\mathrm{BC}$ by centrifugation $(800 \mathrm{~g}$ for $30 \mathrm{~min}$ at 
room temperature, without active brake) over Lymphoprep (Axis-Shield PoC, Oslo, Norway) followed by negative isolation using magnetic beads (Easysep T-cell negative isolation kit, StemCell Technologies), according to the manufacturer's instructions. CD3 positive T lymphocytes were consistently over $90 \%$ of the cells purified using this negative selection method. PBMC were obtained from BC following Lymphoprep density gradient centrifugation as above, and plated on TCPS petri dishes at $5 \times 10^{6}$ cells/ $\mathrm{mL}$ and lymphocytes separated from the monocytic population by a $2 \mathrm{~h}$ adherence step. All cells were cultured in complete culture medium. At the appropriated time points, macrophages and DC cultured on the different substrates were harvested after 20-30 min incubation at 37 or $4{ }^{\circ} \mathrm{C}$ with PBS-5 mM EDTA (Sigma-Aldrich) prior to experiments.

\section{Flow cytometry}

For cell surface staining analysis, freshly isolated monocytes were plated at $0.1 \times 10^{6}$ cells $/ \mathrm{cm}^{2}$ or $0.2 \times$ $10^{6} \mathrm{cells} / \mathrm{cm}^{2}$ and allowed to differentiate into macrophages or DC, respectively. Fully differentiated cells, macrophages at day 10 and DC at day 7, were gently harvested, washed and resuspended in staining buffer (PBS, $2 \%$ FBS, $0.01 \%$ azide). Labelling was performed in a final volume of $50 \mu \mathrm{L}$ with the indicated fluorescently conjugated antibodies for $45 \mathrm{~min}$ at $4{ }^{\circ} \mathrm{C}$ in the dark. Cells were then washed three times with staining buffer and transferred to FACS tubes for analysis by flow cytometry. The following antibodies were used: anti-CD1a (PE and APC), anti-CD3 (FITC and PE), anti-CD4-APC, anti-CD8-PE, anti-CD14 (FITC, PE and APC), anti-CD86-FITC, HLA-DR-PE (all from Immunotools, Friesoythe, Germany), anti-CD69-FITC (Dako, Glostrup, Denmark), anti-CD83-FITC (AbD Serotec, Kidlington, UK), anti-CD163-PE and antiCD206-Cy5 (both from R\&D Systems, Minneapolis, $\mathrm{MN}$, USA). Isotype matched antibodies were used as negative controls, to define background staining. To assess cell viability, macrophages and DC were first stained, as described above, for the lineage markers CD14 or CD1a, respectively, then incubated with Annexin V-FITC and propidium iodide for $15 \mathrm{~min}$ (BD Biosciences) and finally analysed by flow cytometry. Fluorescence was measured using a FACS Calibur flow cytometer (BD Biosciences) with Cell Quest software, and 10,000 events were collected per sample. Analysis was performed using Flow Jo software. Mean fluorescence intensity (MFI) values were calculated by subtracting the respective isotype control.

\section{Cytokine production}

For cytokine evaluation, freshly isolated monocytes were seeded at $0.125 \times 10^{6}$ cells $/ \mathrm{cm}^{2}$ on TCPS or Ch films and cell culture supernatants from 3-, 7- and 10-day differentiated macrophages and 7-day differentiated DC, on both substrates, were collected, centrifuged to remove cell debris, and assayed for IL-1 $\beta$, IL-6, IL-10, IL-23, TNF- $\alpha$ and TGF- $\beta 1$ production by ELISA (Legend Max Human ELISA kits, all from BioLegend, San Diego, CA, USA), according to the manufacturer's protocol. IL-12 production was determined using the Quantikine anti-human IL-12imunoassay (R\&D Systems). Sample concentrations (pg/
$\mathrm{mL}$ ) were determined from the mean absorbance values for each set of samples, compared to a standard calibration curve. The examination of DC cell culture supernatants at shorter time points was not performed, as these cells require 5-7 d to fully differentiate (Babensee and Paranjpe, 2005; Chapuis et al., 1997).

\section{Gelatin zymography}

The same cell culture supernatants used for ELISA were analysed by gelatin zymography in $0.1 \%$ gelatin type B (Sigma-Aldrich) -10\% polyacrylamide- (BioRad, Hercules, CA, USA) gels. 10 or $20 \mu \mathrm{g}$ protein (for macrophages or DC, respectively) were prepared in SDS sample buffer and run, without denaturation, at $60 \mathrm{~V}$, $100 \mathrm{~mA}$. After electrophoresis, gels were washed twice with $2 \%$ Triton X-100 (Sigma-Aldrich) for $15 \mathrm{~min}$ on an orbital shaker to remove SDS remnants. Gels were then incubated for $16 \mathrm{~h}$ in appropriate matrix metalloproteinase (MMP) substrate buffer, washed in distilled water, stained with Coomassie Brilliant Blue R-250 solution (SigmaAldrich) for approximately $30 \mathrm{~min}$ and finally transferred to distilled water. MMP activity was quantified by calculating for each band the pixel intensity per $\mathrm{mm}^{2}$, using the QuantityOne software (Bio-Rad).

\section{Cell motility}

Cell movement was evaluated on both Ch films and TCPS and monitored for $12 \mathrm{~h}$ using time-lapse video microscopy. Macrophages differentiated for 3, 7 or $10 \mathrm{~d}$ and DC differentiated for $7 \mathrm{~d}$ in TCPS were gently detached with PBS-EDTA, and allowed to adhere to $\mathrm{Ch}$ films or TCPS for $2 \mathrm{~h}$ at $37^{\circ} \mathrm{C}$ and $5 \% \mathrm{CO}_{2}$ atmosphere. Bright field images were then captured on 5 distinct microscopic areas every 5 min using a $20 \mathrm{x}$ objective of an automated inverted Zeiss Zx2 microscope (Carl Zeiss, Oberkochen, Germany) and a digital charge-coupled camera. A time-lapse sequence was formed by merging individual images and 12 cells, at least, were randomly chosen for quantification of distance travelled. Cell tracking was performed using FiJi software.

\section{Analysis of T cell proliferation}

Monocytes isolated as described above were plated on Ch films or TCPS at $0.03 \times 10^{6}$ cells $/ \mathrm{cm}^{2}$, with or without differentiating cytokines, for DC or macrophages, respectively. T lymphocytes were counted with a Neubauer chamber and the required number of cells was diluted for $1 \times 10^{7}$ cells $/ \mathrm{mL}$ and labelled with $1 \mu \mathrm{M}$ carboxyfluorescein diacetate succinimidyl ester (CFSE, Invitrogen) at $37{ }^{\circ} \mathrm{C}$ for $15 \mathrm{~min}$ in $\mathrm{PBS}$, followed by two washes $(5 \mathrm{~min}$ at $2500 \mathrm{rpm}$ ) with PBS supplemented with $20 \%$ FBS for fluorescence quenching. T cells were then resuspended in complete medium and $0.9 \times 10^{6}$ cells were added to each well containing $0.3 \times 10^{6}$ monocytes (3:1 ratio) (Huber et al., 2010; Larsen et al., 1994; Mangi and Kantor, 1975; Scheinecker et al., 1998), or left alone on the substrates in presence or absence of the same cytokines used to differentiate DC. Also, peripheral blood lymphocyte samples from the same donor as purified $\mathrm{T}$ cells were stimulated with phytohaemmaglutinin (PHA) (SigmaAldrich), a mitogenic agent, as a positive proliferation control. After $7 \mathrm{~d}$ of co-culture, cells were harvested 
A
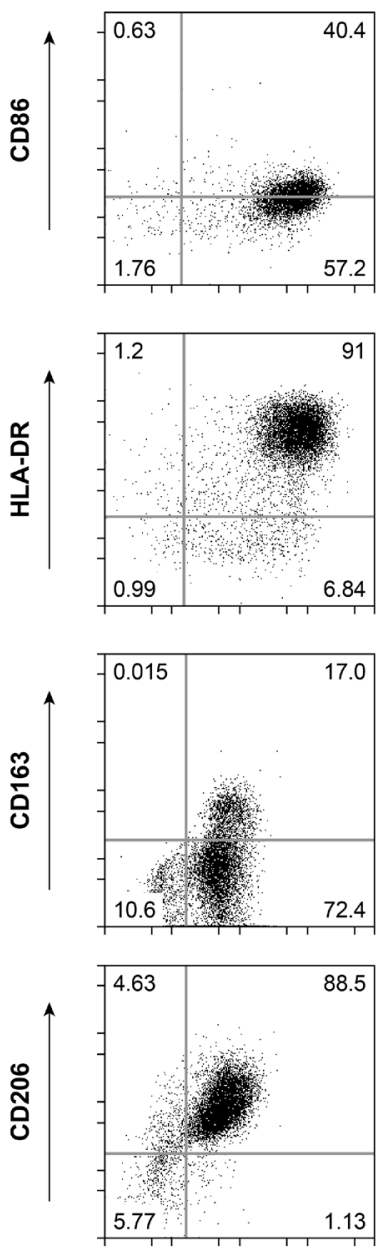

Ch
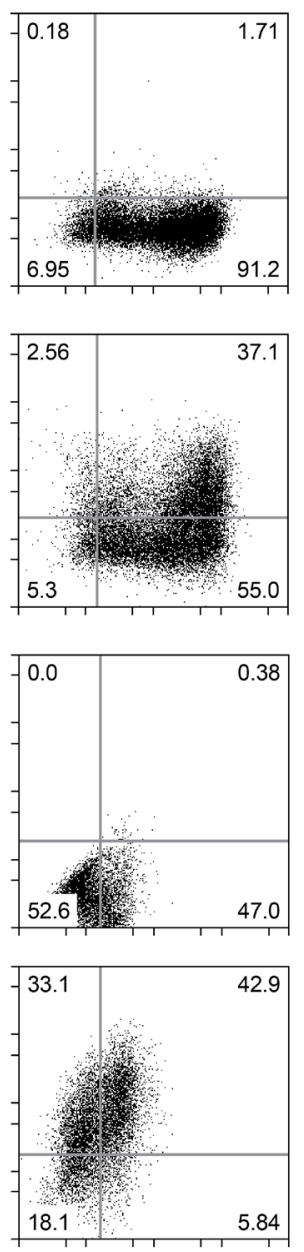

IL-10

(anti-inflammatory MФ) (pro-inflammatory MФ)
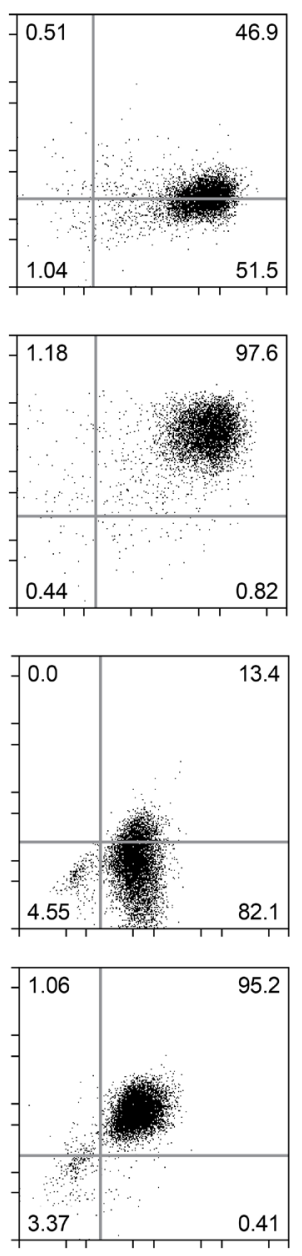

0.41
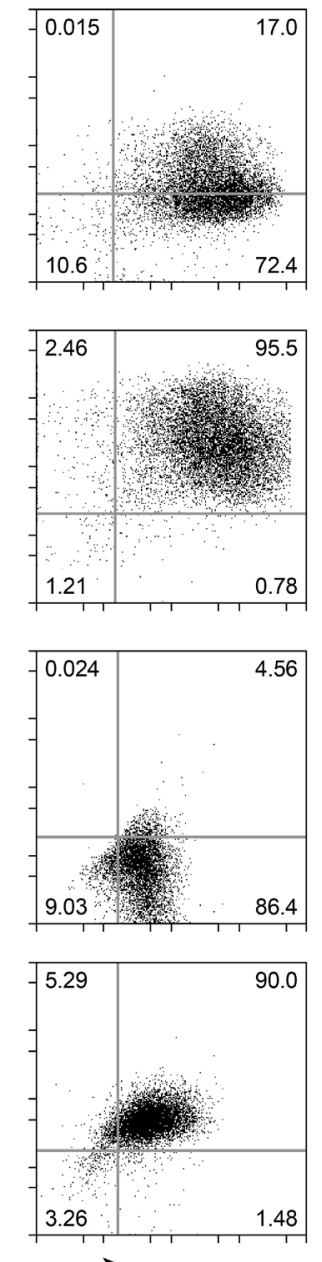

CD14

B
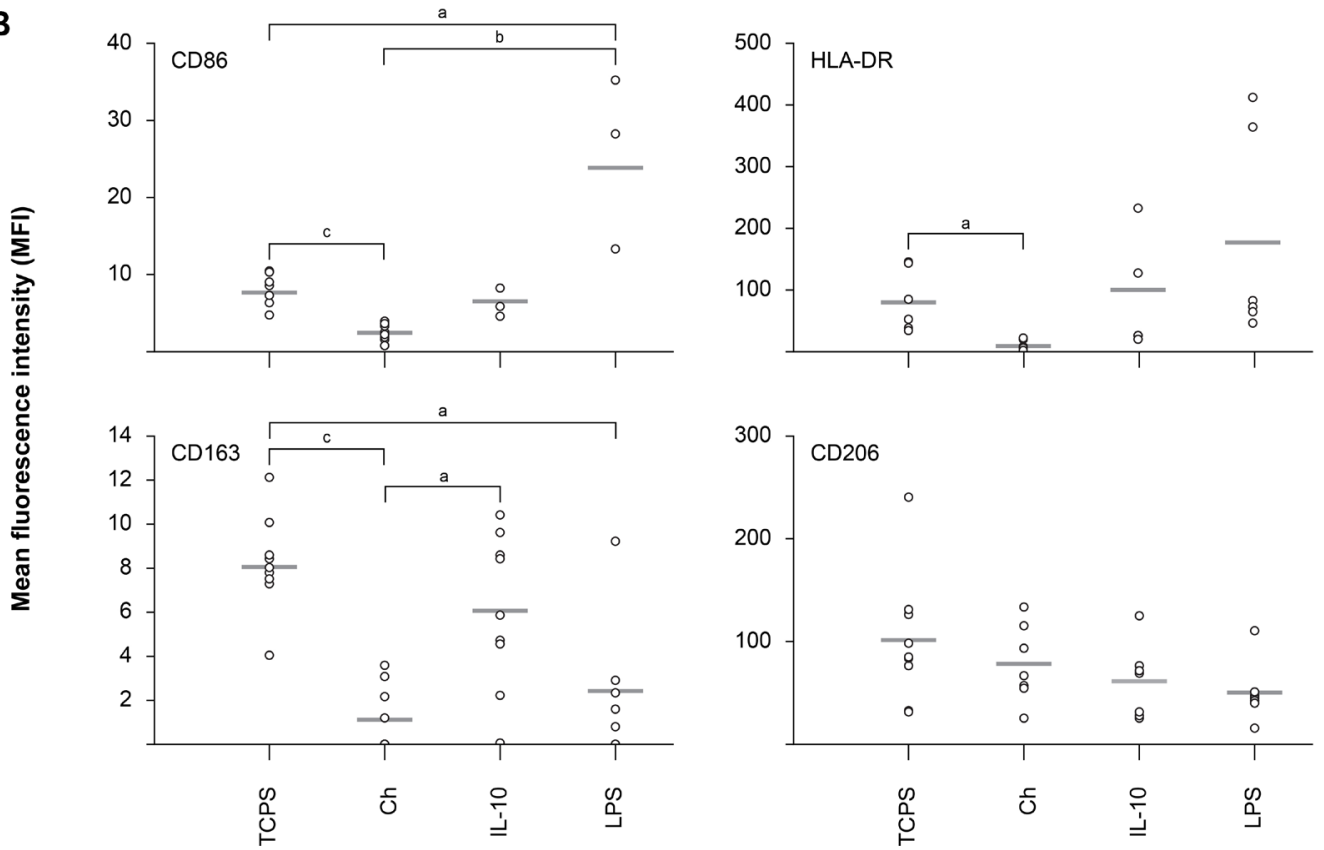

Fig. 2. Expression of cell surface markers of macrophages differentiated on Ch films. (A) Human primary monocytederived macrophages, differentiated for $10 \mathrm{~d}$, were harvested and cell surface stained with the indicated antibodies before FACS analysis. LPS or IL-10 stimulation was also performed on cells cultured on TCPS for control purposes. (B) Scatter charts represent the mean fluorescence intensity (MFI) for each cell surface marker from, at least, 3 different donors. Superscripts indicate statistically significant difference $\left({ }^{a} p<0.05 ;{ }^{b} p<0.01 ;{ }^{c} p<0.001\right)$. MФ, macrophages; TCPS, tissue culture polystyrene; Ch, chitosan; IL-10, interleukin-10; LPS, lipopolysaccharide. 
and cell surface-labelled, as described above, with antiCD3-PE conjugated antibodies to evaluate specific $T$ cell proliferation. Unlabelled $\mathrm{T}$ lymphocytes were used to perform isotype control stainings. A single CD3-PE staining, and cells labelled with CFSE alone were used as single stainings, to define sample compensation. Samples were acquired in a FACS Calibur (BD Biosciences) using Cell Quest software, and further analysed with FlowJo software. T cell division was determined by the extent of CFSE halving on CD3 positive cells.

\section{Statistical analysis}

Statistical analysis was performed using Prism5 software, v5.0a. Results were analysed for Gaussian distribution using the D'Agostino and Pearson normality test and samples were non-parametric. The Mann-Whitney test was used to compare two samples, whereas comparison between more than two samples was performed using the Kruskal-Wallis test followed by Dunns comparison test. A value of $p<0.05$ was considered statistically significant: ${ }^{a} p<0.05 ;{ }^{b} p<0.01 ;{ }^{c} p<0.001$. Data are presented showing all individual donors and the respective mean, or as mean $\pm \mathrm{SD}$.

\section{Results}

\section{Chitosan stimulates both macrophages and DC}

The potential of $\mathrm{Ch}$ to act as an immunostimulatory substrate, via its influence on macrophages and DC, was investigated by allowing the differentiation of their precursors, monocytes, directly on Ch films. Isolation of monocytes by negative selection resulted on a highly enriched $\mathrm{CD} 14^{+}$monocytic population, with no detectable contamination by $\mathrm{CD}^{+} \mathrm{T}$ lymphocytes (Fig. 1A). This ensured that the cellular responses analysed are cell type specific, and not the result of intercellular crosstalk. DC and macrophage differentiation were allowed to take place for 7 or $10 \mathrm{~d}$, respectively, on Ch films or control TCPS. As shown in Fig. 1B, both cell types displayed high cell viability on Ch substrates. In addition, positive controls of LPS stimulation to induce DC maturation and IL-10 or LPS treatment to commit macrophages into anti-inflammatory (M2c) or pro-inflammatory (M1) phenotypes, respectively, were also performed with cells cultured on TCPS. Importantly, no exogenous cytokines were added to promote macrophage differentiation. The ability of $\mathrm{Ch}$ to modulate macrophage polarisation was evaluated by cell surface expression of specific phenotypic markers for human polarised macrophages, together with the lineage marker CD14. Dot plots from a representative experiment are depicted in Fig. 2A, and the MFI, calculated over at least 3 different biological replicates is presented in Fig. 2B. After $10 \mathrm{~d}$ of differentiation on Ch films, macrophages significantly down-regulated $(p<0.05)$ the expression of the M1 phenotypic markers CD86 and MHCII (HLA-DR), in contrast to that observed following LPS stimulation (Fig. 2A and B). Intriguingly, when the M2 phenotypic markers CD163 (scavenger receptor) and CD206 (mannose receptor) were evaluated, a decrease in the expression levels of CD163 was also observed on
Ch in comparison with cells cultured on TCPS. In fact, very few macrophages differentiated on $\mathrm{Ch}$ expressed CD163, whereas a significant percentage still retained CD206 expression at the cell surface (Fig. 2A and B). This was also accompanied by a decrease in the levels of the monocytic lineage marker CD14, for cells cultured on $\mathrm{Ch}$, when compared with TCPS (Fig. 2A), which has been associated with the progression of macrophage differentiation (Steinbach and Thiele, 1994), indicating that this polymer may accelerate macrophage maturation. In agreement with previous reports, both CD163 and CD206 displayed high basal levels of expression, which were differentially affected by IL-10 or LPS stimuli (Fig. 2B); while LPS induced a significant decrease in cell surface expression of CD163 $(p<0.05)$, CD206 was not significantly altered by LPS or IL-10 (Porcheray et al., 2005). Statistically significant differences between cells cultured on Ch relative to culture on TCPS were found for the expression of CD86 $(p<0.001)$, HLA-DR $(p<0.05)$, and CD163 $(p<0.001)$.

Besides macrophages, monocytes can also differentiate into DC, another cell population with a key role in innate and adaptive immunity. Thus, the activation status of Ch-differentiated DC was next evaluated by measuring the up-regulation of a classical DC activation marker, CD83, as well as of the co-stimulatory molecule CD86 and the MHCII molecule HLA-DR. In addition, CD1a was used as a DC lineage marker. As shown in Fig. 3, Ch induced a statistically significant $(p<0.05)$ up-regulation of CD86 expression on cells from six different donors. As expected, LPS induced a greater up-regulation of this cell surface molecule ( $p<0.001)$ (Fig. 3A and B). Although $\mathrm{Ch}$ induced a partial up-regulation of CD83 and a decrease of HLA-DR expression, as illustrated in Fig. 3A, no statistically significant differences were found for the levels of expression of both markers on $\mathrm{Ch}$, when compared with TCPS control, as opposed to LPS stimulation, which induced significant increases of CD83 and MHCII expression on DC cultured on TCPS ( $p<0.001$ for CD83 and $p<0.05$ for MHCII) (Fig. 3B).

\section{Chitosan modulates macrophage and DC cytokine production pattern}

To better understand how $\mathrm{Ch}$ affects the differentiation and activation of monocyte-derived cells, the cytokines produced by both macrophages and DC differentiated on this substrate were evaluated across at least 6 different individuals. The cytokine profile for M1 and M2 macrophage phenotypes has been established, and together with the expression pattern of cell surface molecules, can be used to characterise different population subsets. When macrophages were cultured on $\mathrm{Ch}$, they increased the production of pro-inflammatory cytokines, at early differentiation stages, in comparison with control TCPS conditions (Fig. 4A). Levels of both TNF- $\alpha$ and IL-1 $\beta$ were significantly higher at day 3 , for cells cultured on $\mathrm{Ch}$ than on TCPS. However, if we compare only cells cultured on $\mathrm{Ch}$ with time, there is a reduction of the levels of all pro-inflammatory cytokines tested, with TNF- $\alpha$ being statistically lower between days 3 and 10 of culture (Fig. 4A). Secretion of pro-inflammatory IL-12 and IL- 
A
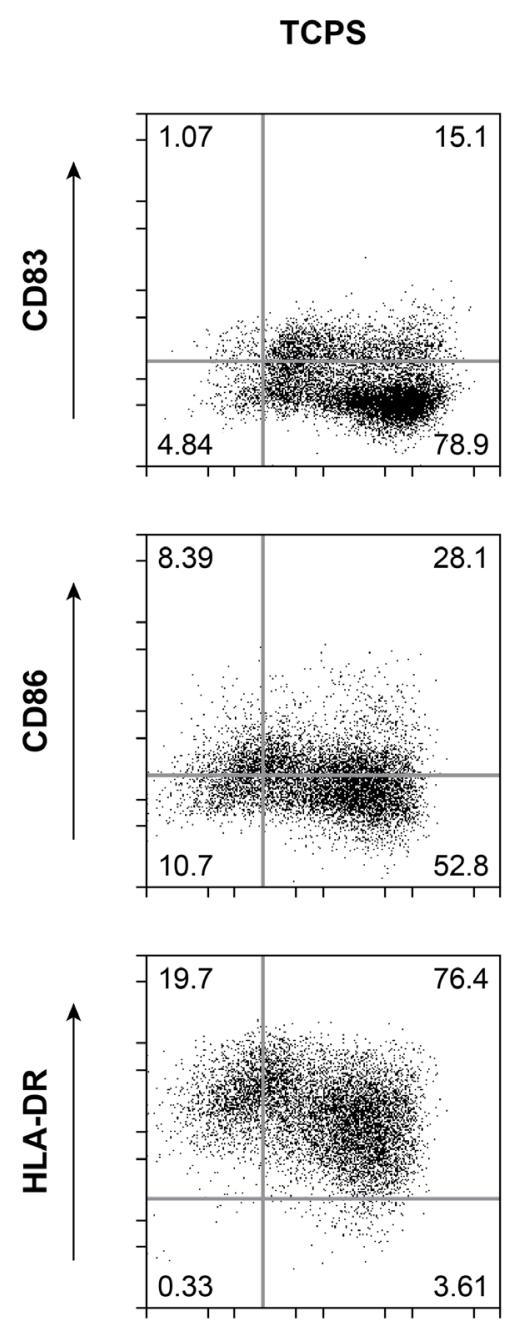

Ch
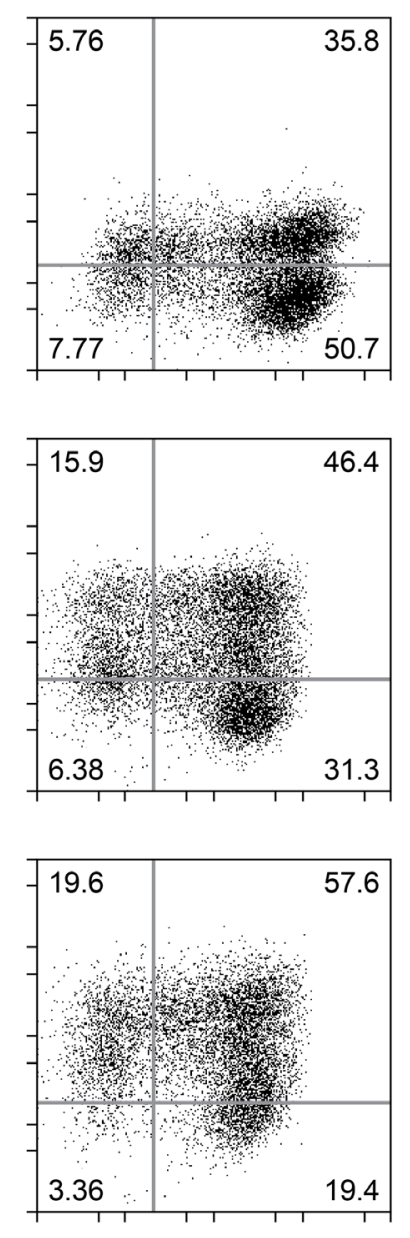

CD1a

B

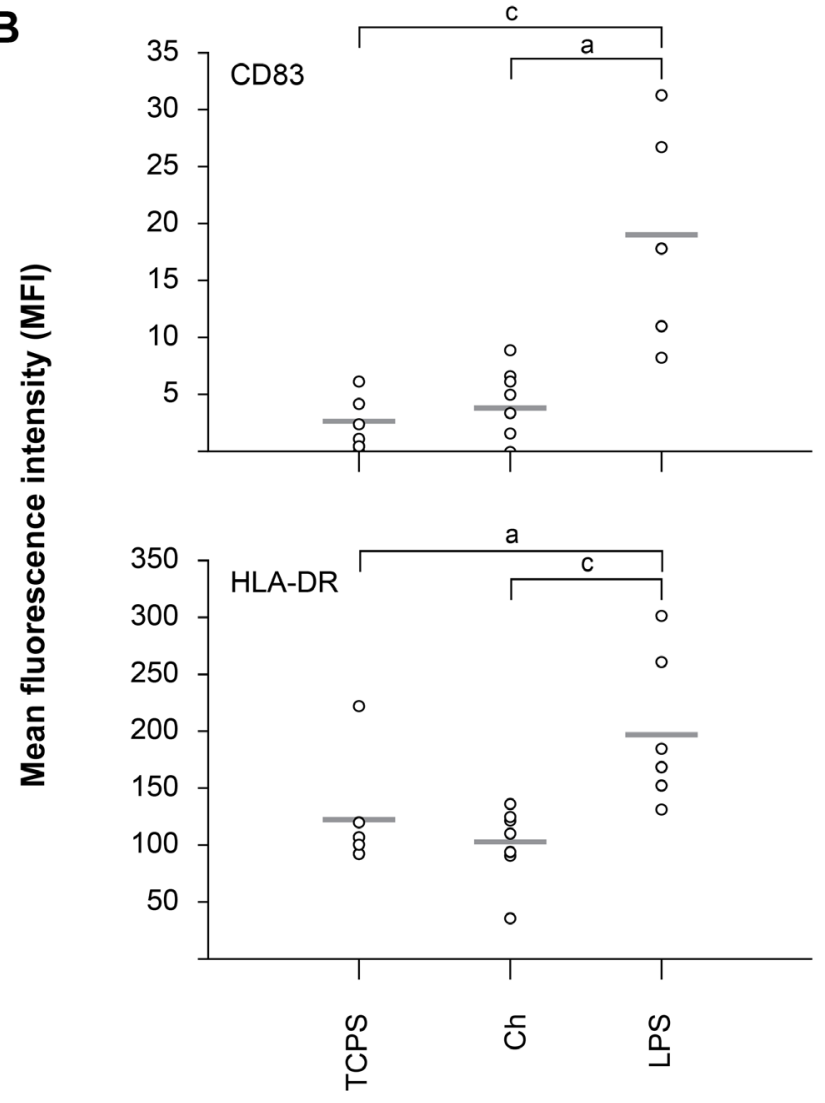

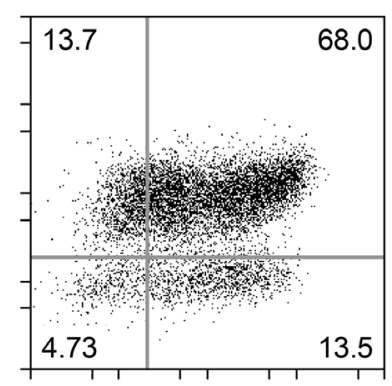

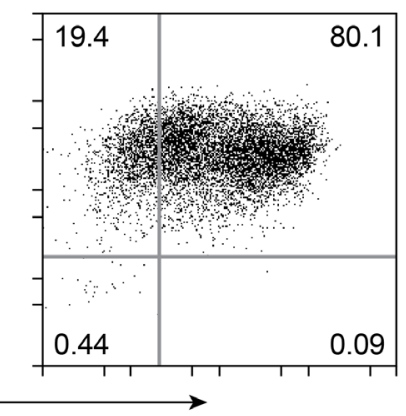

LPS

(pro-inflammatory DC)
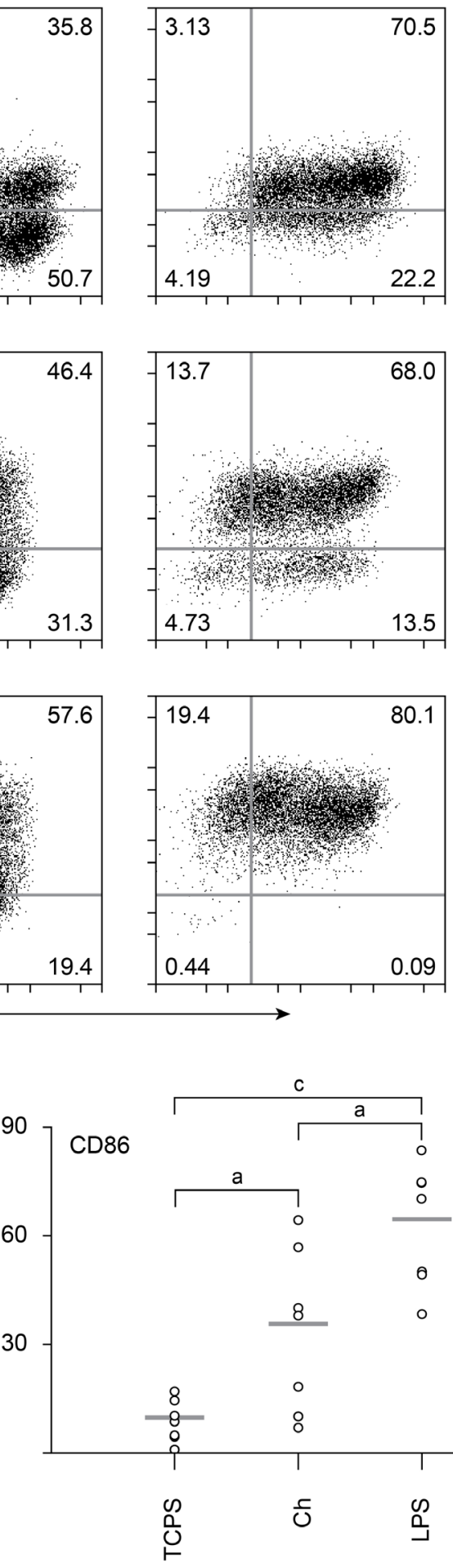

Fig. 3. Expression of cell surface markers of dendritic cells differentiated on Ch films. (A) Human primary monocyte-derived DC, differentiated for $7 \mathrm{~d}$, were harvested and cell surface stained with the indicated antibodies before FACS analysis. LPS was used as a positive control on cells cultured on TCPS. (B) Scatter charts represent the mean fluorescence intensity (MFI) for each cell surface marker from, at least, 6 different donors. Superscripts indicate statistically significant difference $\left({ }^{a} p<0.05 ;{ }^{b} p<0.01 ;{ }^{c} p<0.001\right)$. DC, dendritic cells. TCPS, tissue culture polystyrene; Ch, chitosan; LPS, lipopolysaccharide. 

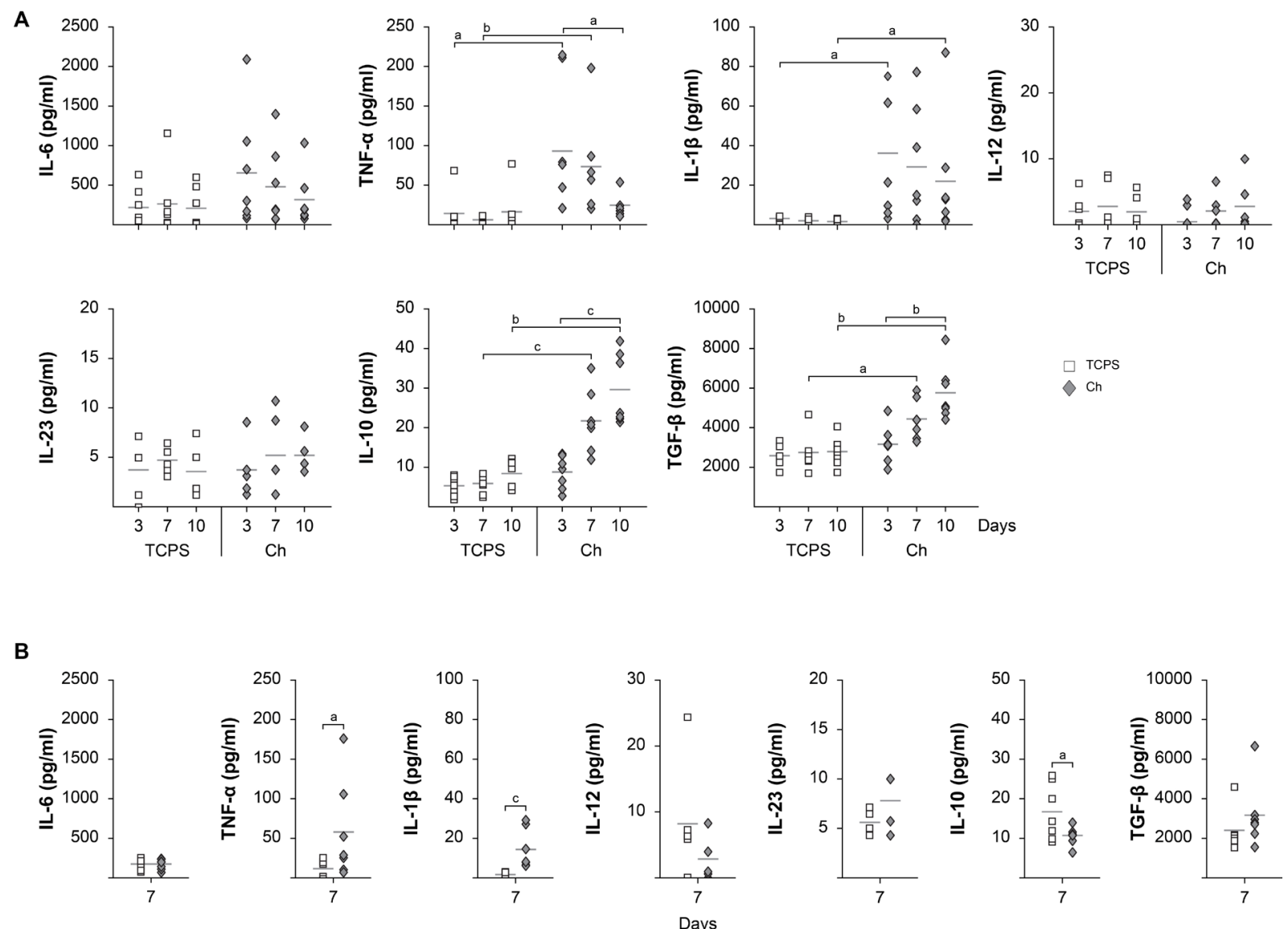

Fig. 4. Cytokine production by Ch-differentiated macrophages and DC. Cytokine release was determined by ELISA, using cell culture supernatants from 3,7 or $10 \mathrm{~d}$ differentiated human primary monocyte-derived macrophages (A) or $7 \mathrm{~d}$ differentiated human primary monocyte-derived DC (B). Superscripts indicate statistically significant difference $\left({ }^{a} p<0.05 ;{ }^{b} p<0.01 ;{ }^{c} p<0.001\right)$. Open squares represent TCPS samples while grey diamonds correspond to chitosan samples. Responses were determined from cells, of at least, 6 different donors. TCPS, tissue culture polystyrene; Ch, chitosan.

23 on Ch was low during the entire culture period (Fig. 4A). In contrast, $\mathrm{Ch}$ induced a significant up-regulation of anti-inflammatory cytokines IL-10 and TGF- $\beta 1$ at later differentiation stages, and when compared to TCPS. Importantly, in contrast to the gradual reduction observed for anti-inflammatory cytokine release during macrophage differentiation on Ch films, the levels of both IL-10 and TGF- $\beta 1$ production augmented with increasing times on Ch (3.5 fold increase for IL-10 and 1.8 fold increase for TGF- $\beta 1$ from day 3 to day 10) (Fig. 4A).

Although IL-6 release by DC was not affected by the substrate (Fig. 4B), Ch significantly stimulated the production of pro-inflammatory cytokines TNF- $\alpha$ $(p<0.05)$ and IL-1 $\beta(p<0.001)$, with levels 4.6 and 11.4 fold higher than on TCPS, respectively (Fig. 4B). This was in clear contrast to the pattern observed for the same cytokines on fully differentiated macrophages, i.e. at day 10 (Fig. 4A). Moreover, unlike macrophages, Ch-differentiated DC significantly down-regulated the secretion of IL-10 in comparison with TCPS. Nonetheless, IL-12 and IL-23 were found to be residual for both cell types independently of the substrate used. Finally, like macrophages, DC increased the secretion of TGF- $\beta 1$ when cultured on $\mathrm{Ch}$, albeit to a lesser extent.

\section{Chitosan enhances the activity of MMP9 released by macrophages, but not by $\mathrm{DC}$}

Cells of the monocyte/macrophage lineage, including DC, are active producers of MMPs (Goetzl et al., 1996; Webster and Crowe, 2006). Thus, in order to further characterise the populations of macrophages and DC present during cell differentiation on Ch films, the activity of MMP2 and MMP9 was determined, at different time points, by gelatin zymography. The results of three independent experiments using different donors show that throughout monocyte differentiation to macrophages, the levels of the pro-form of MMP9 are higher on Ch films compared to control conditions (Fig. 5A). Moreover, at later differentiation stages, i.e. at days 7 and 10 , differences were also observed for the active form of MMP9, which gradually increased (Fig. 5A). In terms of MMP2 activity, only one band, corresponding to the pro-form of the enzyme, could be observed and, in contrast with MMP9, no differences were detected with macrophage differentiation on both substrates (Fig. 5A). Furthermore, the activity of both MMP2 and MMP9 produced by DC does not seem to be influenced by culture on Ch films (Fig. 5B). 
A

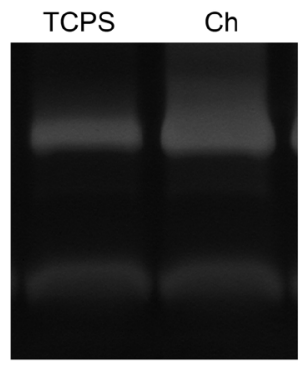

Day 3

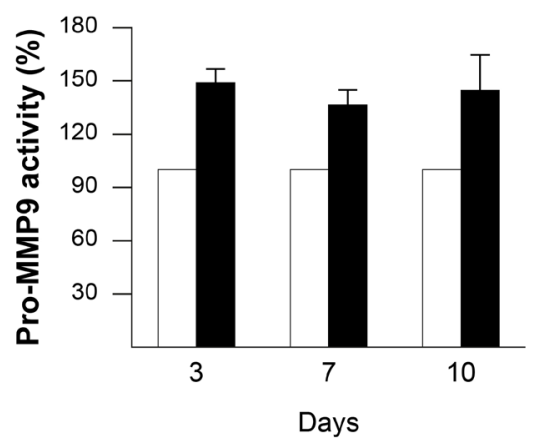

B

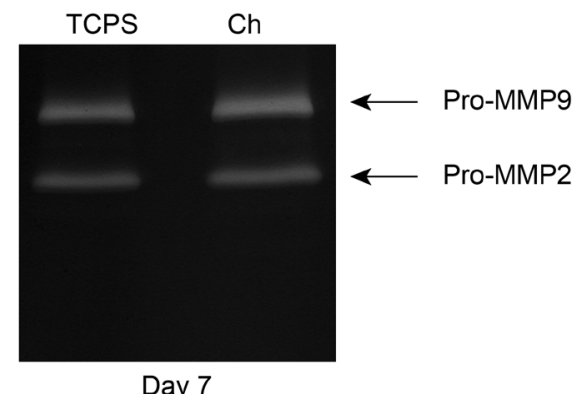

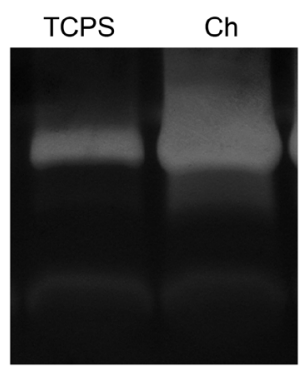

Day 7
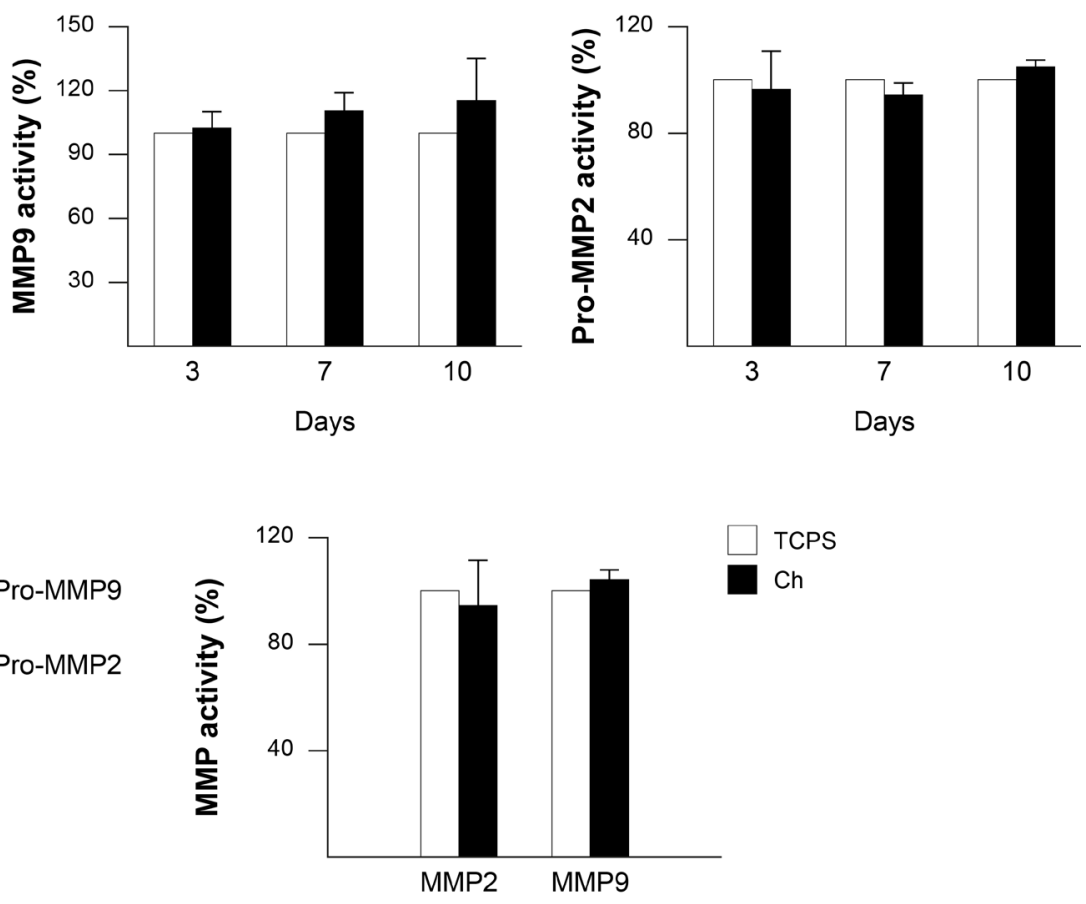

Fig. 5. Activity of MMPs from macrophages and DC cultured on Ch films. Supernatants from macrophages and DC cultured for different time periods on Ch or TCPS were analysed by gelatin zymography. A representative gel of three independent experiments for MMP9 and MMP2 secretion by macrophages (A) or DC (B) is depicted. Quantitative assessment of the two proteolytic enzymes is also illustrated for macrophages (A-lower panels) and for DC (B-right panel). Results are expressed as a percentage of MMP activity of TCPS differentiated cells. TCPS, tissue culture polystyrene; Ch, chitosan; MMP, matrix metalloprotease.

Chitosan increases the migratory behaviour of macrophages without affecting DC migration

MMP9 activity has been previously described to assist the migration of monocytes and DC (Webster and Crowe, 2006), so we sought to investigate whether $\mathrm{Ch}$ has the potential to affect the migratory behaviour of these cell populations, by evaluating cell migration upon contact with $\mathrm{Ch}$ films. Thereby, cells at distinct stages of differentiation were monitored for $12 \mathrm{~h}$ by time-lapse video microscopy. The recorded images were merged to form a time-lapse sequence and trajectories analysed to determine the distance covered by each cell. Cell tracking indicates that at days 3 and 7 monocytes/macrophages have increased migratory behaviour, moving longer distances and at a higher speed on Ch than on TCPS control (Fig. $6 \mathrm{~A})$. In addition, the average step length, i.e. the average distance covered per frame, was also higher on $\mathrm{Ch}$ than on TCPS. However, with progression of differentiation macrophages show reduced migratory capacity, and when fully differentiated, are slower and migrate significantly less on Ch films than on TCPS control $(p<0.05)$ (Fig. 6A). Conversely, upon contact with the substrates, DC do not show any significant differences (Fig. 6B). Nevertheless, on $\mathrm{Ch}$ the distance, average step length and velocity were higher for differentiated DC (day 7) than for fully differentiated macrophages (day 10). In fact, the migratory behaviour of DC is similar to that of macrophages at day 7 of differentiation (Fig. 6).

\section{Ch-activated macrophages and DC do not promote significant $\mathrm{T}$ cell proliferation}

Having established that $\mathrm{Ch}$ renders macrophages and DC active and affects their cytokine profile, it was important to address whether this biomaterial was able to trigger an APC-mediated T lymphocyte activation and consequently an adaptive immune response. The stimulatory capacity of $\mathrm{Ch}$, per se, on lymphocytes was firstly evaluated. After $20 \mathrm{~h}$ of exposure to $\mathrm{Ch}$ films, the levels of the early 


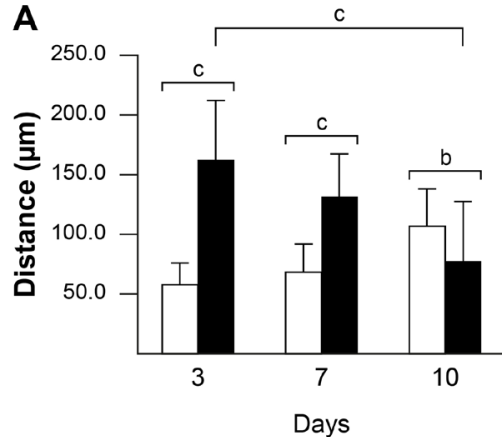

B

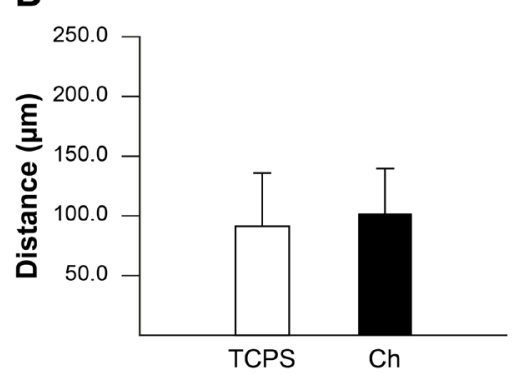

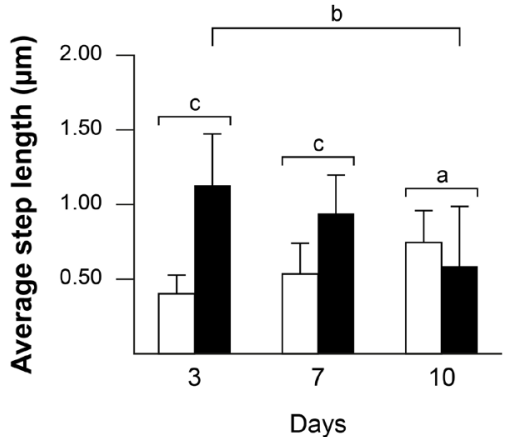
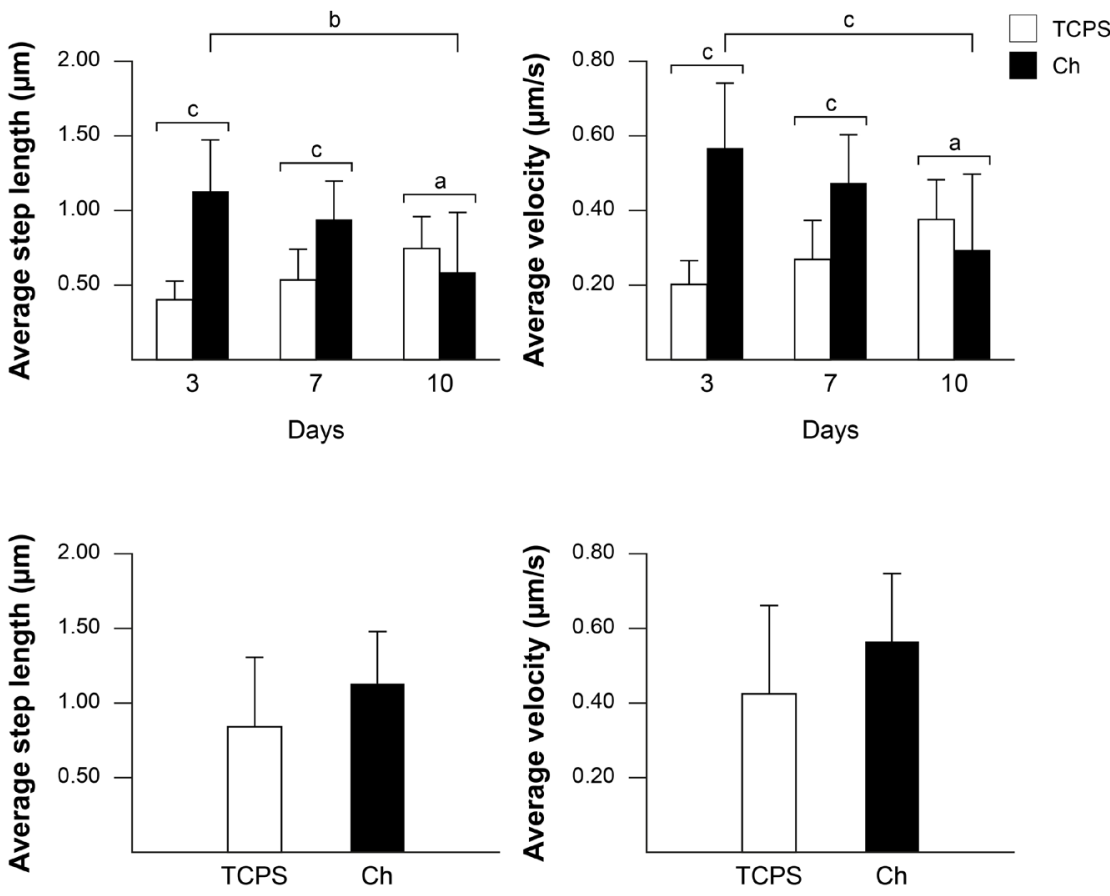

Fig. 6. Migratory behaviour of macrophages and DC on Ch. Human primary monocyte-derived macrophages differentiated for 3, 7 or $10 \mathrm{~d}$ or monocyte-derived DC cultured for $7 \mathrm{~d}$ in TCPS were transferred to chitosan films or new TCPS wells, and allowed to adhere for $2 \mathrm{~h}$ before being monitored for $12 \mathrm{~h}$ using time-lapse video microscopy. Each frame was merged to produce a time-lapse sequence and cells were tracked for the total distance travelled. Distance, average step length and average velocity of macrophages (A) or DC (B) were determined using FIJI software. Error bars represent standard deviation of, at least, 12 cells per condition and superscripts indicate statistically significant difference $\left({ }^{a} p<0.05 ;{ }^{b} p<0.01 ;{ }^{c} p<0.001\right)$. TCPS, tissue culture polystyrene; $\mathrm{Ch}$, chitosan.

T lymphocyte activation marker CD69 were measured and found to be similar to TCPS control, with only very few $\mathrm{CD}^{+} \mathrm{T}$ cells expressing CD69 (Fig. 7A). This is in clear contrast with PHA-stimulated lymphocytes used as positive control, where most $\mathrm{T}$ cells expressed CD69. To address Ch-induced macrophage and DC functionality, mixed lymphocyte reactions were set up and $\mathrm{T}$ lymphocyte proliferation evaluated. The results obtained show that the highest percentage of T lymphocyte proliferation occurred when these cells were in contact with DC, either on TCPS or Ch substrates (Fig. 7B). Notably, lymphocytes alone or with DC differentiating cytokines tend to divide just once, whereas a small percentage of those cultured with DC or macrophages divide many times (G5+). In Fig. 7C the percentage of $\mathrm{T}$ lymphocytes that divided, across six independent experiments, is presented. Despite the slightly higher T cell proliferation when either macrophages or DC were differentiated and co-cultured with $\mathrm{T}$ cells, on $\mathrm{Ch}$ as compared to TCPS, no significant differences were found (Fig. 7C). The levels of T cell proliferation observed in all conditions tested were well below the strong non-specific response induced by PHA (Fig. 7B).

\section{Discussion}

In this study, for the first time, macrophages and DC were differentiated from the same precursor cells, directly on $\mathrm{Ch}$ films for 10 or $7 \mathrm{~d}$, respectively, in order to elucidate the influence of this polymer on cell behaviour. In contrast to other reports, cell-Ch interactions were not evaluated after a short exposure but during all the differentiation process and when $\mathrm{Ch}$ is presented as a substrate. In addition, despite various studies performed with macrophages, to the best of our knowledge none has addressed Ch-induced macrophage polarisation, very few involved dendritic cells and none made a comparison between the pro- and anti-inflammatory cytokines secreted by both. Absence of exogenous cytokines, other than those required for inducing DC differentiation from monocytes, assures that the observed responses result only from biomaterial stimulation and are not pre-conditioned. The data obtained supports and extends previous reports on Ch-induced macrophage and DC activation, but most of all indicates that $\mathrm{Ch}$ is capable of modulating macrophage polarisation towards an M2 phenotype, while driving a more proinflammatory DC differentiation. The responses elicited by $\mathrm{Ch}$ on macrophages and DC showed differences and similarities, although a more pronounced effect was found on macrophages.

When a device is implanted, monocytes - and not fully differentiated cells - are recruited and adhere to the implant surface, subsequently differentiating into macrophages (Anderson et al., 2008) or potentially DC (León et al., 2005). Interaction of both macrophages and DC with biomaterials in vivo has been demonstrated previously 
A
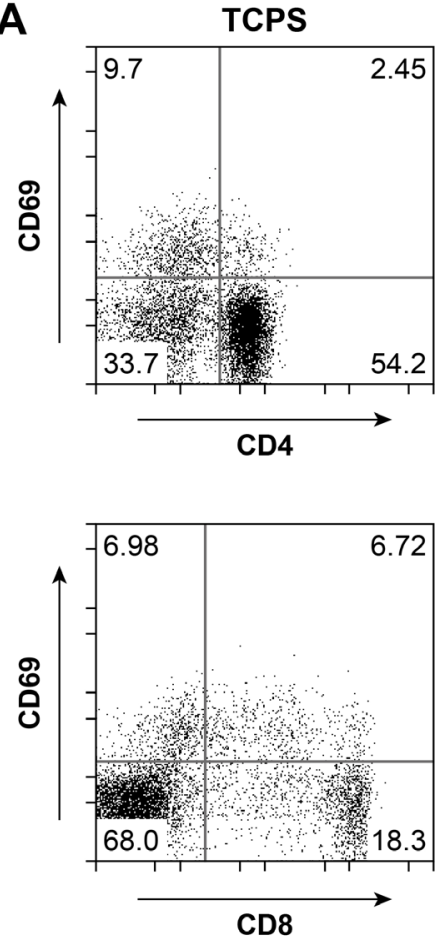

B

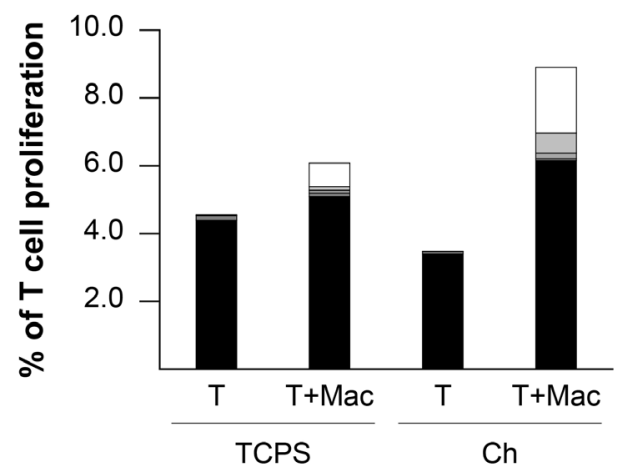

C

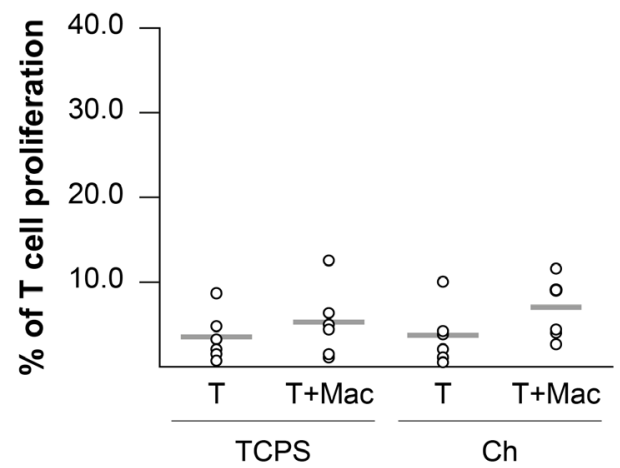

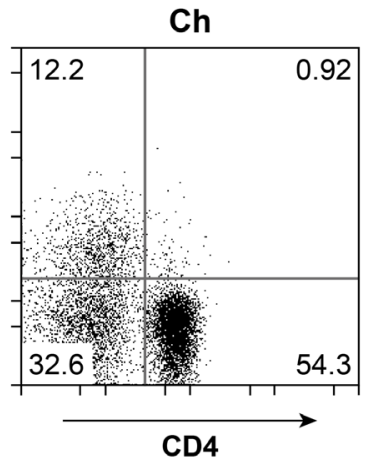
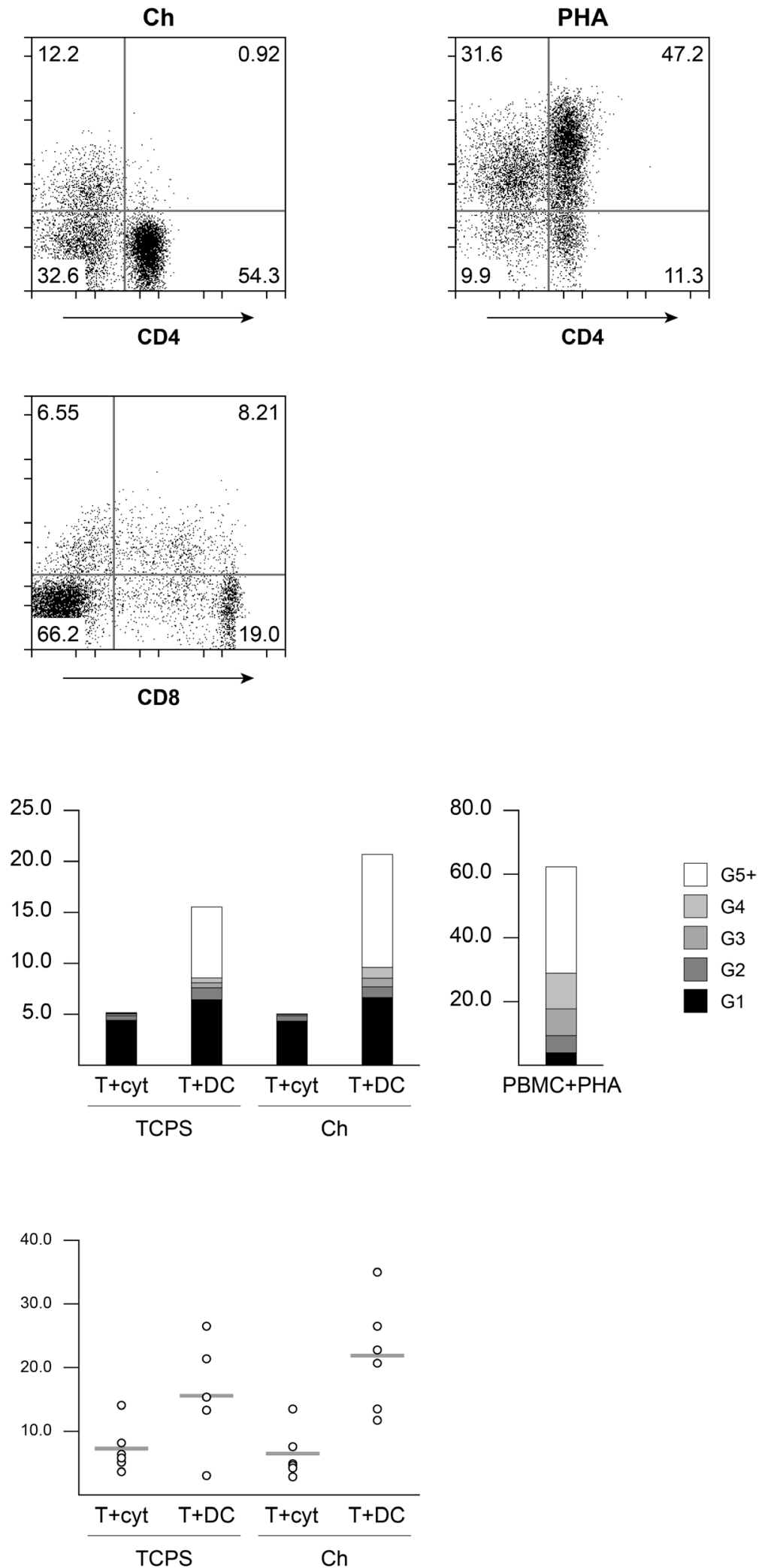

Fig. 7. $\mathrm{T}$ cell activation and proliferation in response to $\mathrm{Ch}$ films or to antigen-presenting cells differentiated on distinct substrates. (A) Peripheral blood lymphocytes were cultured on $\mathrm{Ch}$ for $20 \mathrm{~h}$, harvested and double stained for the early activation marker CD69 and CD4 or CD8 to identify specific T cell subsets. PHA was used as positive control. (B, C) To evaluate T cell proliferation, mixed lymphocyte reactions were set up on Ch and TCPS and T cell proliferation evaluated by CFSE halving of $\mathrm{CD}^{+}$cells after $7 \mathrm{~d}$ of co-culture. Unpurified lymphocytes from the same donor as purified T cells were stimulated with PHA for control purposes. The percentage of T cells in each generation (B) and the percentage of T cells that divided at least once for each of 6 independent experiments (C) are depicted. TCPS, tissue culture polystyrene; $\mathrm{Ch}$, chitosan; T, T lymphocytes; Mac, macrophages; DC, dendritic cells; cyt, cytokines; PHA, phytohaemmaglutinin; PBMC, peripheral blood mononuclear cells. 
(Anderson et al., 2008; Babensee, 2008) and is likely crucial for the development of a foreign body reaction. Therefore, to more closely mimic physiological conditions, studies involving the interaction between macrophages and biomaterials have been performed during 10-14 d of culture, directly on the substrate under investigation (Anderson et al., 2008; Ariganello et al., 2011; Dinnes et al., 2008). Such an approach allows monitoring of cellular changes at different stages of differentiation, thus enabling a full characterisation of biomaterial-mediated effects. As for DC, $7 \mathrm{~d}$ are reported to be necessary to analyse their full differentiation and potential maturation in response to a given stimulus (Babensee and Paranjpe, 2005; Chapuis et al., 1997). Thus, this time-point was chosen for analysing the effects of Ch on DC. In this study, the purity of the starting monocytic population was carefully considered, since low purity might have compromised the interpretation of specific cell-biomaterial interactions, given that cellular cross-talk between distinct cell populations has been reported to regulate each other's behaviour (Brodbeck et al., 2005; Chang et al., 2009). By using highly enriched monocytes we specifically addressed the ability of $\mathrm{Ch}$ to modulate macrophage and DC differentiation, with phenotypic and functional changes resulting only from substrate stimulation.

$\mathrm{Ch}$ is a natural biodegradable polymer with putative immunological properties, shown to enhance the function of different cell types, such as polymorphonuclear leukocytes, macrophages and fibroblasts (Mori et al., 1997; Peluso et al., 1994; Porporatto et al., 2003; Ueno et al., 2001b). It accelerates the infiltration of inflammatory cells in vivo, as well as the production of biological mediators, and also enhances wound healing (Barbosa et al., 2010; Ueno et al., 2001a; Ueno et al., 2001c; VandeVord et al., 2002). Upon implantation, $\mathrm{Ch}$ has been reported to have a high degree of biocompatibility in different conditions and to lead to an inflammatory reaction that depends on the DA of the polymer (Azab et al., 2007; Kim et al., 2011; VandeVord et al., 2002; Yussof et al., 2011). The DA of Ch used in this study $(\mathrm{DA}=11 \%)$ is below the range described in the literature as inducing marked inflammation (Barbosa et al., 2010; Hidaka et al., 1999; Tomihata and Ikada, 1997). In fact, Ch implants with the same DA did not induce prolonged or exacerbated inflammatory responses throughout the implantation period (Yussof et al., 2011).

In this report, we present evidence that macrophages polarise into an M2c-like phenotype in response to Ch stimulation. This conclusion was based essentially on the combined analysis of cell surface markers and cytokine secretion profile. Down-regulation of cell surface MHCII and the co-stimulatory molecule CD86, was the first indication excluding an M1-pro-inflammatory polarisation (Mantovani et al., 2004). Importantly, within the anti-inflammatory M2 phenotype, only the M2c subset includes cells devoid of MHCII at the cell surface (Kou and Babensee, 2011; Mantovani et al., 2004). Similarly, the different levels of cell surface expression detected on Ch for CD206 and CD163, commonly used as M2 phenotypic markers, point to an M2c-like polarisation. In fact, of the three M2 subsets, both M2a and M2c express CD206 (Mantovani et al., 2004), as do approximately
$43 \%$ of $\mathrm{CD} 14^{+} \mathrm{Ch}$-differentiated macrophages. Moreover, our results agree with a previous report showing that the levels of CD206 are not affected by several pro- and antiinflammatory stimuli, including LPS or IL-10 (Porcheray et al., 2005), and this appears also to be the case for $\mathrm{Ch}$. The discrepancy between our data and that of Ueno et al. (2001a), who demonstrated that murine peritoneal macrophages up-regulate the expression of CD206 after being treated for $6 \mathrm{~h}$ with Ch-supplemented media, may not only be species-driven, but simply lie on the time and way the stimulating agent was presented to the cells. Since the $\mathrm{N}$-acetyl-glucosamine residues of $\mathrm{Ch}$ can interact with CD206, it is conceivable that in a short-term interaction, macrophages recognise $\mathrm{Ch}$ via CD206, thereby increasing its expression at the surface (Han et al., 2005). Nonetheless, after $10 \mathrm{~d}$ of culture on $\mathrm{Ch}$, expression and activity of this receptor may be differently modulated by divergent mechanisms, possibly important during macrophage differentiation and cellular activation (Fiani et al., 1998). Regarding CD163, its increased expression is more associated with the M2a class and not with M2b or M2c (Mantovani et al., 2004). The reduced levels of CD163 found on $\mathrm{Ch}$ could also result from increased secretion of TGF- $\beta 1$ promoted by this substrate, that we and others (Ueno et al., 2001c) observe, since TGF- $\beta$ acts as a negative regulator of CD163 expression by macrophages (Pioli et al., 2004). Although many authors have reported and still consider up-regulation of CD163 following IL-10 treatment as indicative of an M2 phenotype, this is frequently associated with the addition of M-CSF to promote macrophage differentiation, as this cytokine has been shown to enhance CD163 expression (Porcheray et $a l ., 2005)$. In this study no differences were found between control conditions and IL-10 stimulation, probably because no exogenous cytokines were used to induce macrophage differentiation. Notably, despite the down-regulation of all phenotypic expression markers investigated, macrophages remained viable (as shown by Annexin and PI staining) and exhibited normal morphology during the entire culture period (data not shown), indicating that the cell surface marker profile observed is a specific Ch-induced effect, and is not related to a loss of cell viability.

Besides membrane receptors, macrophage polarisation is associated with other distinctive gene expression signatures, which include soluble factors and effector molecules (Martinez et al., 2008). The levels of three pro-inflammatory cytokines, IL- 6 , TNF- $\alpha$ and IL- $1 \beta$, on Ch substrates progressively decreased over time, whereas anti-inflammatory IL-10 concentration increased up to day 10 . When the early differentiation time of $3 \mathrm{~d}$ was compared with $10 \mathrm{~d}$ of culture on $\mathrm{Ch}$, a statistically significant decrease of TNF- $\alpha(p<0.05)$ and increase of IL-10 $(p<0.001)$ secretion was observed. This gradual increase of IL-10 may explain the reduced levels of proinflammatory counterparts at later stages of macrophage differentiation, since IL-10 inhibits the production of several soluble mediators, including IL-6, TNF- $\alpha$ and IL-1 $\beta$ (Gordon, 2003). Regarding the pro-inflammatory cytokines IL-12 and IL-23, secretion levels measured on Ch were always low, which is a characteristic of M2 macrophages. Most importantly, macrophages cultured on $\mathrm{Ch}$ were found 
to significantly increase the levels of the anti-inflammatory cytokine TGF- $\beta 1$, described to be produced at elevated levels by M2c macrophages (Mantovani et al., 2004). To the best of our knowledge there is no available data concerning cytokine profiles elicited by Ch scaffolds or Ch-coated implants. Nonetheless, our results concur with what has been previously observed for other forms of Ch in vivo. When given orally, Ch up-regulated IL-4 and TGF- $\beta$ mRNA expression and augmented IL-10 release at the mucosal levels (Porporatto et al., 2005). Moreover, macrophage expression of IL-1, TNF- $\alpha$ and INF- $\gamma$ at the mRNA and protein levels are promoted by $\mathrm{Ch}$, both in vitro and in vivo after a short-term stimulation (Feng et al., 2004; Guzmán-Morales et al., 2011; Nishimura et al., 1986; Wei et al., 2009). In this study, we also found an increase of pro-inflammatory cytokine production triggered by $\mathrm{Ch}$ at early monocyte to macrophage differentiation (day 3 of culture). Still, our time-course investigation revealed that progression of macrophage differentiation correlated with a decrease in pro-inflammatory cytokines, suggesting an M2like macrophage polarisation. Previous reports have also demonstrated that in vitro monocyte/macrophage cytokine profiles may vary with biomaterial surface chemistry (Ariganello et al., 2011; Brodbeck et al., 2002; Gretzer et al., 2003; Schutte et al., 2009a). Of particular relevance to our studies were the observations of Jones and co-workers, who have reported a phenotypic switch of biomaterialadherent macrophages over time to a phenotype that is close to that of alternatively activated macrophages, with down-regulation of IL- $1 \beta$ and IL-6, among others, and concomitant production of IL-10 (Jones et al., 2007). Interestingly, a quantitative in vivo cytokine analysis showed a decrease of IL- $1 \beta$ together with an increase of IL-10 and TGF- $\beta$ over the implantation period using different synthetic biomedical polymers (Rodriguez et al., 2009). Nevertheless, IL-6 and TNF- $\alpha$ levels varied with time, and with the polymer used (Rodriguez et al., 2009). This indicates that distinct material-dependent cytokine profiles are associated with macrophages and foreign body giant cells in vivo. Likewise, evaluation of cytokine responses systemically (Walschus et al., 2012) and from exudate fluids surrounding chemically distinct materials (Brodbeck et al., 2003; Schutte et al., 2009b) evidenced material-specific differences, particularly on IL-6, IL-10 and IL-13. Noteworthy, monocyte/macrophages purified from the foreign body reaction $3 \mathrm{~d}$ post-implantation upregulated IL-1 $\beta$, IL-6, IL-10 and TNF- $\alpha$ gene expression (Mesure et al., 2010). Lastly, recent in vivo analysis of cytokine expression around implanted materials revealed the presence of IL-4, IL-13 and IL-10 in close proximity to the implant, which together with IL- 6 and TGF- $\beta$, colocalised with small macrophages (Higgins et al., 2009).

To further confirm the M2c macrophage polarisation on $\mathrm{Ch}$, supported by the cell surface marker expression pattern and cytokine secretion profile, production and activity of MMPs, which are described as being higher in M2 macrophages (Lolmede et al., 2009), were analysed by gelatin zymography. Ch enhanced the activity of MMP9 produced by macrophages with time, without affecting that of MMP2. This reveals the specificity of this polymer in modulating macrophage MMP9 activity and corroborates previous studies reporting the production of MMPs in a biomaterial-dependent manner (Jones et al., 2008). There was some MMP9 production by TCPS-differentiated macrophages, as expected, because cell adherence has been shown to induce significant levels of this enzyme (Webster and Crowe, 2006). MMPs are involved in distinct processes, including regulation of cytokine activity and shedding of cell surface molecules (Webster and Crowe, 2006), such as CD163 and CD206 (Fabriek et al., 2007; Martínez-Pomares et al., 1998). Also, MMP9 has been suggested to participate in phagocytosis and degradation of Ch-DNA nanoparticles (Webster and Crowe, 2006). Nonetheless, a correlation between increasing MMP9 activity levels found on $\mathrm{Ch}$ and its degradation are beyond the scope of this study. However, as this enzyme also contributes to extracellular matrix remodelling and facilitates cellular migration, the migratory behaviour of monocytes/macrophages and DC placed in contact with $\mathrm{Ch}$, at distinct differentiation stages, was evaluated. Cell motility analysis was the only assay in this study where cells were placed on $\mathrm{Ch}$ films upon differentiation. This was performed to allow us to assess substrate modulation of early migratory events taking place immediately after exposure of macrophage or DC to $\mathrm{Ch}$. Moreover, it avoids possible interference in migration caused by previous cell adherence. Our results showed that the overall migratory ability of macrophages on $\mathrm{Ch}$ films decreases with their phenotypic progression, suggesting enhanced cell adhesion over time. This may result from alterations to specialised adhesion structures, such as podosomes, which have been shown to occur during macrophage differentiation (DeFife et al., 1999) and to be biomaterial-dependent for both macrophages and DC (Rogers and Babensee, 2011).

Contrary to macrophages, supernatants of DC differentiated on Ch films versus TCPS did not show differences in MMP9 activity. This agrees with the similar migratory ability of DC cultured on Ch films as compared to control surfaces, as increased MMP9 is known to enhance DC migration (Webster and Crowe, 2006). Regarding DC cytokine profile, Ch elicited significant increases of both TNF- $\alpha$ and IL- $1 \beta$, in comparison to cells cultured on TCPS, a different response to that observed for fully differentiated macrophages. The morphology of DC cultured on $\mathrm{Ch}$ revealed that the polymer activates these cells (data not shown), which, together with a significant reduction of IL-10 secretion and up-regulation of the co-stimulatory molecule CD86, point towards a proinflammatory response by DC. However, this appears not to be a classical pro-inflammatory response, as levels of IL-12 and IL-23, two main pro-inflammatory cytokines, remained low and levels of TGF- $\beta 1$ increased. These events may be inter-related, since TGF- $\beta$ induces downregulation of IL-12 (Fainaru et al., 2007), which shares a subunit with IL-23 (Oppmann et al., 2000). Moreover, the similar expression levels found for the activation marker CD83 and MHCII molecule HLA-DR on Ch and TCPS, as previously reported (Babensee and Paranjpe, 2005), also support this assumption.

In this study, we also investigated the action of $\mathrm{Ch}$ on $\mathrm{T}$ cells, which were used to assess DC and macrophage functional characteristics. T cells, by themselves, 
were poorly triggered by $\mathrm{Ch}$, as demonstrated by the scarce expression of CD69 and low proliferation when cultured alone on Ch films. As expected, a small T cell population responds to allogeneic macrophages or DC by proliferating. However, when several pairs of donors were analysed, no significant differences were found between the proliferation rates of $\mathrm{T}$ cells stimulated by $\mathrm{DC}$ or macrophages differentiated on $\mathrm{Ch}$ substrates, in relation to the basal proliferation rates induced by unstimulated cells, differentiated just on TCPS. Thus, despite some level of macrophage and DC activation on $\mathrm{Ch}$, this does not seem to translate into the induction of an adaptive immune response, characterised by increased $\mathrm{T}$ lymphocyte proliferation. Notably however, this moderate level of DC maturation supported by $\mathrm{Ch}$ possibly explains the observed adjuvant effect of the polymer in the immune response towards associated antigens (Slütter et al., 2010), a strategy currently used for vaccine delivery using polymers like Ch (Arca et al., 2009; Kang et al., 2009). Although DC have been shown in vivo to transport $\mathrm{Ch}$ to lymph nodes when the polymer is administered orally (Porporatto et al., 2005), and to be present at the implant site when PLGA scaffolds were used (Babensee, 2008), further experiments are necessary to show DC interaction with Ch scaffolds in vivo. In such a scenario, Ch may be able to influence the immune response to biological components of allogenic or xenogenic origin incorporated in the biomaterial, by acting as an adjuvant capable of inducing immunity (Arca et al., 2009; Kang et al., 2009; van der Lubben et al., 2001), or promoting tolerance, as reported by Porporatto and co-workers (Porporatto et al., 2009). In the case of this study, we observe a slight activation of DC without significant induction of $\mathrm{T}$ cell proliferation, together with a macrophage phenotypic switch over time and significant amounts of TGF- $\beta 1$ produced by both cell populations. This is likely to result in a more anti-inflammatory environment, promoting wound healing and tissue repair, towards enhanced integration of the biomaterial, as previously described (Kim et al., 2011; VandeVord et al., 2002; Yussof et al., 2011).

Altogether, the findings presented herein suggest that Ch affects differently macrophage and DC differentiation and modulates macrophage polarisation. As M1 and M2 macrophages represent extremes along a continuum that includes multiple phenotypes (Mantovani et al., 2004), one can suggest that the position assumed by Chdifferentiated macrophages in this spectrum would be close to the M2c phenotype. As for DC differentiated on Ch films, they seem to adopt a more pro-inflammatory phenotype when challenged by $\mathrm{Ch}$. Based on all the results obtained we hypothesise that an overall proinflammatory reaction associated to a particular biomaterial may sometimes hide the expression of anti-inflammatory cytokines, which may be of relevance for tissue repair/ regeneration. In addition, combined secretion of the strong pleiotropic mediator TGF- $\beta 1$ from both cell types upon $\mathrm{Ch}$ stimulation, suggests that $\mathrm{Ch}$ should have some inherent, although perhaps limited, ability to support tissue repair/ regeneration. Control of macrophage and DC phenotype from pro-inflammatory to regulatory/tolerogenic is of much interest for tissue engineering applications. Subsequent modification of this polymer with appropriate agents may further enhance $\mathrm{Ch}$ ability to modulate cell polarisation and constitute a strategy for faster and improved woundhealing and tissue repair.

\section{Conclusion}

This work analysed the influence of $\mathrm{Ch}$, as a substrate, on the differentiation of two distinct cell populations with a common precursor: macrophages and monocyte-derived DC. By allowing cellular differentiation to occur directly on $\mathrm{Ch}$, it was found that, with time, this polymer induced a phenotypic switch on macrophages to an activation state similar to an M2c polarisation. In addition, Ch elicited DC pro-inflammatory activation without leading to significant $\mathrm{T}$ cell proliferation. Taken together, our results indicate different outcomes for the related cell populations studied, with likely implications for the host response following implantation. These data highlight the need for dissecting the effects of biomaterials on different inflammatory cell populations, which is of particular relevance in the design of biomaterials capable of stimulating tissue repair/ regeneration through proper tuning of pro- and antiinflammatory responses.

\section{Acknowledgements}

The authors would like to thank Instituto Português do Sangue (IPS) for kindly donating the buffy coats. This work was supported by POPH/QREN 2007-2013 and the Fundação para a Ciência e a Tecnologia (FCT) ((Project PTDC/SAU-BEB/099954/2008). MIO is recipient of a post-doctoral fellowship from FCT-POPH (SFRH/ BPD/37090/2007). SGS and MJO have research positions funded by FCT-POPH-FSE (Ciência 2007). We wish to confirm that there are no known conflicts of interest associated with this publication and there has been no significant financial support for this work that could have influenced its outcome.

\section{References}

Anderson JM, Jones JA (2007) Phenotypic dichotomies in the foreign body reaction. Biomaterials 28: 5114-5120.

Anderson JM, Rodriguez A, Chang DT (2008) Foreign body reaction to biomaterials. Semin Immunol 20: 86-100.

Arca HÇ, Günbeyaz M, Şenel S (2009) Chitosan-based systems for the delivery of vaccine antigens. Expert Rev Vaccines 8: 937-953.

Ariganello MB, Simionescu DT, Labow RS, Michael Lee J (2011) Macrophage differentiation and polarization on a decellularized pericardial biomaterial. Biomaterials 32: 439-449.

Azab AK, Doviner V, Orkin B, Kleinstern J, Srebnik M, Nissan A, Rubinstein A (2007) Biocompatibility evaluation of crosslinked chitosan hydrogels after subcutaneous and intraperitoneal implantation in the rat. J Biomed Mater Res A 83A: 414-422. 
Babensee JE (2008) Interaction of dendritic cells with biomaterials. Semin Immunol 20: 101-108.

Babensee JE, Paranjpe A (2005) Differential levels of dendritic cell maturation on different biomaterials used in combination products. J Biomed Mater Res A 74A: 503510 .

Babensee JE, Anderson JM, McIntire LV, Mikos AG (1998) Host response to tissue engineered devices. Adv Drug Deliver Rev 33: 111-139.

Baldrick P (2010) The safety of chitosan as a pharmaceutical excipient. Regul Toxicol Pharm 56: 290299.

Banchereau J, Briere F, Caux C, Davoust J, Lebecque S, Liu Y-J, Pulendran B, Palucka K (2000) Immunobiology of dendritic cells. Annu Rev Immunol 18: 767-811.

Barbosa JN, Amaral IF, Águas AP, Barbosa MA (2010) Evaluation of the effect of the degree of acetylation on the inflammatory response to 3D porous chitosan scaffolds. J Biomed Mater Res A 93A: 20-28.

Brodbeck WG, Nakayama Y, Matsuda T, Colton E, Ziats NP, Anderson JM (2002) Biomaterial surface chemistry dictates adherent monocyte/macrophage cytokine expression in vitro. Cytokine 18: 311-319.

Brodbeck WG, Voskerician G, Ziats NP, Nakayama Y, Matsuda T, Anderson JM (2003) In vivo leukocyte cytokine mRNA responses to biomaterials are dependent on surface chemistry. J Biomed Mater Res A 64A: 320-329.

Brodbeck WG, MacEwan M, Colton E, Meyerson H, Anderson JM (2005) Lymphocytes and the foreign body response: Lymphocyte enhancement of macrophage adhesion and fusion. J Biomed Mater Res A 74A: 222-229.

Chang DT, Colton E, Anderson JM (2009) Paracrine and juxtacrine lymphocyte enhancement of adherent macrophage and foreign body giant cell activation. J Biomed Mater Res A 89A: 490-498.

Chapuis F, Rosenzwajg M, Yagello M, Ekman M, Biberfeld P, Gluckman JC (1997) Differentiation of human dendritic cells from monocytes in vitro. Eur J Immunol 27: 431-441.

Crompton K, Tomas D, Finkelstein D, Marr M, Forsythe J, Horne M (2006) Inflammatory response on injection of chitosan/GP to the brain. J Mater Sci Mater Med 17: 633-639.

Dash M, Chiellini F, Ottenbrite RM, Chiellini E (2011) Chitosan-A versatile semi-synthetic polymer in biomedical applications. Prog Polym Sci 36: 981-1014.

DeFife KM, Jenney CR, Colton E, Anderson JM (1999) Cytoskeletal and adhesive structural polarizations accompany IL-13-induced human macrophage fusion. J Histochem Cytochem 47: 65-74.

Dinnes DLM, Santerre JP, Labow RS (2008) Influence of biodegradable and non-biodegradable material surfaces on the differentiation of human monocyte-derived macrophages. Differentiation 76: 232-244.

Fabriek BO, Møller HJ, Vloet RPM, van Winsen LM, Hanemaaijer R, Teunissen CE, Uitdehaag BMJ, van den Berg TK, Dijkstra CD (2007) Proteolytic shedding of the macrophage scavenger receptor CD163 in multiple sclerosis. J Neuroimmunol 187: 179-186.

Fainaru O, Shay T, Hantisteanu S, Goldenberg D, Domany E, Groner Y (2007) TGF[beta]-dependent gene expression profile during maturation of dendritic cells. Genes Immun 8: 239-244.

Feng J, Zhao L, Yu Q (2004) Receptor-mediated stimulatory effect of oligochitosan in macrophages. Biochem Biophys Res Commun 317: 414-420.

Fiani ML, Beitz J, Turvy D, Blum JS, Stahl PD (1998) Regulation of mannose receptor synthesis and turnover in mouse J774 macrophages J Leukoc Biol 64: 85-91.

Goetzl E, Banda M, Leppert D (1996) Commentary: Matrix metalloproteinases in immunity. J Immunol 156: 1-4.

Gordon S (2003) Alternative activation of macrophages. Nat Rev Immunol 3: 23-35.

Gretzer C, Gisselfält K, Liljensten E, Rydén L, Thomsen P (2003) Adhesion, apoptosis and cytokine release of human mononuclear cells cultured on degradable poly(urethane urea), polystyrene and titanium in vitro. Biomaterials 24: 2843-2852.

Guzmán-Morales J, Ariganello MB, Hammami I, Thibault M, Jolicoeur M, Hoemann CD (2011) Biodegradable chitosan particles induce chemokine release and negligible arginase-1 activity compared to IL-4 in murine bone marrow-derived macrophages. Biochem Biophys Res Commun 405: 538-544.

Han Y, Zhao L, Yu Z, Feng J, Yu Q (2005) Role of mannose receptor in oligochitosan-mediated stimulation of macrophage function. Int Immunopharmacol 5: 15331542.

Hidaka Y, Ito M, Mori K, Yagasaki H, Kafrawy AH (1999) Histopathological and immunohistochemical studies of membranes of deacetylated chitin derivatives implanted over rat calvaria. J Biomed Mater Res 46: 418423.

Higgins DM, Basaraba RJ, Hohnbaum AC, Lee EJ, Grainger DW, Gonzalez-Juarrero M (2009) Localized immunosuppressive environment in the foreign body response to implanted biomaterials. Am J Pathol 175: 161-170.

Huber S, Hoffmann R, Muskens F, Voehringer D (2010) Alternatively activated macrophages inhibit T-cell proliferation by Stat6-dependent expression of PD-L2. Blood 116: 3311-3320.

Jones JA, Chang DT, Meyerson H, Colton E, Kwon IK, Matsuda T, Anderson JM (2007) Proteomic analysis and quantification of cytokines and chemokines from biomaterial surface-adherent macrophages and foreign body giant cells. J Biomed Mater Res A 83A: 585-596.

Jones JA, McNally AK, Chang DT, Qin LA, Meyerson H, Colton E, Kwon ILK, Matsuda T, Anderson JM (2008) Matrix metalloproteinases and their inhibitors in the foreign body reaction on biomaterials. J Biomed Mater Res A 84A: 158-166.

Kang ML, Cho CS, Yoo HS (2009) Application of chitosan microspheres for nasal delivery of vaccines. Biotechnol Adv 27: 857-865.

Kim I-Y, Seo S-J, Moon H-S, Yoo M-K, Park I-Y, Kim B-C, Cho C-S (2008) Chitosan and its derivatives for tissue engineering applications. Biotechnol Adv 26: 1-21.

Kim H, Tator CH, Shoichet MS (2011) Chitosan implants in the rat spinal cord: Biocompatibility and biodegradation. J Biomed Mater Res A 97A: 395-404. 
Kou PM, Babensee JE (2011) Macrophage and dendritic cell phenotypic diversity in the context of biomaterials. J Biomed Mater Res A 96A: 239-260.

Larsen C, Ritchie S, Hendrix R, Linsley P, Hathcock K, Hodes R, Lowry R, Pearson T (1994) Regulation of immunostimulatory function and costimulatory molecule (B7- 1 and B7-2) expression on murine dendritic cells. J Immunol 152: 5208-5219.

León B, López-Bravo M, Ardavín C (2005) Monocytederived dendritic cells. Semin Immunol 17: 313-318.

Lolmede K, Campana L, Vezzoli M, Bosurgi L, Tonlorenzi R, Clementi E, Bianchi ME, Cossu G, Manfredi AA, Brunelli S, Rovere-Querini P (2009) Inflammatory and alternatively activated human macrophages attract vesselassociated stem cells, relying on separate HMGB1- and MMP-9-dependent pathways. J Leukoc Biol 85: 779-787.

Mangi RJ, Kantor FS (1975) The multiple mixed lymphocyte reaction: variables important in the test as a measure of lymphocyte competence in man. Yale J Biol Med 48: 217-228.

Mantovani A, Sica A, Sozzani S, Allavena P, Vecchi A, Locati M (2004) The chemokine system in diverse forms of macrophage activation and polarization. Trends Immunol 25: 677-686.

Mantovani A, Sica A, Locati M (2005) Macrophage polarization comes of age. Immunity 23: 344-346.

Martínez-Pomares L, Mahoney JA, Káposzta R, Linehan SA, Stahl PD, Gordon S (1998) A functional soluble form of the murine mannose receptor is produced by macrophages in vitro and is present in mouse serum. J Biol Chem 273: 23376-23380.

Martinez FO, Sica A, Mantovani A, Locati M (2008) Macrophage activation and polarization. Front Biosci 13: 453-461.

Mesure L, De Visscher G, Vranken I, Lebacq A, Flameng W (2010) Gene expression study of monocytes/ macrophages during early foreign body reaction and identification of potential precursors of myofibroblasts. PLoS ONE 5: e12949.

Mori T, Okumura M, Matsuura M, Ueno K, Tokura S, Okamoto Y, Minami S, Fujinaga T (1997) Effects of chitin and its derivatives on the proliferation and cytokine production of fibroblasts in vitro. Biomaterials 18: 947-951.

Mori T, Murakami M, Okumura M, Kadosawa T, Uede T, Fujinaga T (2005) Mechanism of macrophage activation by chitin derivatives. J Vet Med Sci 67: 51-56.

Muzzarelli RAA (2009) Chitins and chitosans for the repair of wounded skin, nerve, cartilage and bone. Carbohyd Polym 76: 167-182.

Nishimura K, Ishihara C, Ukei S, Tokura S, Azuma I (1986) Stimulation of cytokine production in mice using deacetylated chitin. Vaccine 4: 151-156.

Oppmann B, Lesley R, Blom B, Timans JC, Xu Y, Hunte B, Vega F, Yu N, Wang J, Singh K, Zonin F, Vaisberg E, Churakova T, Liu M-r, Gorman D, Wagner J, Zurawski S, Liu Y-J, Abrams JS, Moore KW, Rennick D, de WaalMalefyt R, Hannum C, Bazan JF, Kastelein RA (2000) Novel p19 protein engages IL-12p40 to form a cytokine, IL-23, with biological activities similar as well as distinct from IL-12. Immunity 13: 715-725.
Peluso G, Petillo O, Ranieri M, Santin M, Ambrosic L, Calabró D, Avallone B, Balsamo G (1994) Chitosanmediated stimulation of macrophage function. Biomaterials 15: 1215-1220.

Pioli PA, Goonan KE, Wardwell K, Guyre PM (2004) TGF- $\beta$ regulation of human macrophage scavenger receptor CD163 is Smad3-dependent. J Leukoc Biol 76: 500-508.

Porcheray F, Viaud S, Rimaniol AC, Léone C, Samah B, Dereuddre-Bosquet N, Dormont D, Gras G (2005) Macrophage activation switching: an asset for the resolution of inflammation. Clin Exp Immunol 142: 481489.

Porporatto C, Bianco ID, Riera CM, Correa SG (2003) Chitosan induces different 1 -arginine metabolic pathways in resting and inflammatory macrophages. Biochem Biophys Res Comun 304: 266-272.

Porporatto C, Bianco ID, Correa SG (2005) Local and systemic activity of the polysaccharide chitosan at lymphoid tissues after oral administration J Leukoc Biol 78: 62-69.

Porporatto C, Canali MM, Bianco ID, Correa SG (2009) The biocompatible polysaccharide chitosan enhances the oral tolerance to type II collagen. Clin Exp Immunol 155: 79-87.

Rodriguez A, Meyerson H, Anderson JM (2009) Quantitative in vivo cytokine analysis at synthetic biomaterial implant sites. J Biomed Mater Res A 89A: 152-159.

Rogers TH, Babensee JE (2011) The role of integrins in the recognition and response of dendritic cells to biomaterials. Biomaterials 32: 1270-1279.

Sallusto F, Lanzavecchia A(1994) Efficient presentation of soluble antigen by cultured human dendritic cells is maintained by granulocyte/macrophage colony-stimulating factor plus interleukin 4 and downregulated by tumor necrosis factor alpha. J Exp Med 179: 1109-1118.

Santos S, Lynch S, Campbell E, Antoniou A, Powis S (2008) Induction of HLA-B27 heavy chain homodimer formation after activation in dendritic cells. Arthritis Res Ther 10: R100.

Scheinecker C, Machold KP, Majdic O, Höcker P, Knapp W, Smolen JS (1998) Initiation of the autologous mixed lymphocyte reaction requires the expression of costimulatory molecules B7-1 and B7-2 on human peripheral blood dendritic cells. J Immunol 161: 39663973.

Schutte RJ, Parisi-Amon A, Reichert WM (2009a) Cytokine profiling using monocytes/macrophages cultured on common biomaterials with a range of surface chemistries. J Biomed Mater Res A 88A: 128-139.

Schutte RJ, Xie L, Klitzman B, Reichert WM (2009b) In vivo cytokine-associated responses to biomaterials. Biomaterials 30: 160-168.

Slütter B, Soema PC, Ding Z, Verheul R, Hennink W, Jiskoot W (2010) Conjugation of ovalbumin to trimethyl chitosan improves immunogenicity of the antigen. J Control Release 143: 207-214.

Steinbach F, Thiele B (1994) Phenotypic investigation of mononuclear phagocytes by flow cytometry. J Immunol Methods 174: 109-122. 
Tomihata K, Ikada Y (1997) In vitro and in vivo degradation of films of chitin and its deacetylated derivatives. Biomaterials 18: 567-575.

Ueno H, Mori T, Fujinaga T (2001a) Topical formulations and wound healing applications of chitosan. Adv Drug Deliver Rev 52: 105-115.

Ueno H, Murakami M, Okumura M, Kadosawa T, Uede T, Fujinaga T (2001b) Chitosan accelerates the production of osteopontin from polymorphonuclear leukocytes. Biomaterials 22: 1667-1673.

Ueno H, Nakamura F, Murakami M, Okumura M, Kadosawa T, Fujinaga T (2001c) Evaluation effects of chitosan for the extracellular matrix production by fibroblasts and the growth factors production by macrophages. Biomaterials 22: 2125-2130.

van der Lubben IM, Verhoef JC, Borchard G, Junginger HE (2001) Chitosan for mucosal vaccination. Adv Drug Deliver Rev 52: 139-144.

VandeVord PJ, Matthew HWT, DeSilva SP, Mayton L, Wu B, Wooley PH (2002) Evaluation of the biocompatibility of a chitosan scaffold in mice. J Biomed Mater Res 59: 585-590.

Verhasselt V, Buelens C, Willems F, De Groote D, Haeffner-Cavaillon N, Goldman M (1997) Bacterial lipopolysaccharide stimulates the production of cytokines and the expression of costimulatory molecules by human peripheral blood dendritic cells: evidence for a soluble CD14-dependent pathway. J Immunol 158: 2919-2925.

Walschus U, Hoene A, Patrzyk M, Finke B, Polak M, Lucke S, Nebe B, Schroeder K, Podbielski A, Wilhelm L, Schlosser M (2012) Serum profile of pro- and antiinflammatory cytokines in rats following implantation of low-temperature plasma-modified titanium plates. J Mater Sci Mater Med 23: 1299-1307.

Webster NL, Crowe SM (2006) Matrix metalloproteinases, their production by monocytes and macrophages and their potential role in HIV-related diseases. J Leukoc Biol 80: 1052-1066.

Wei X, Wang Y, Zhu Q, Xiao J, Xia W (2009) Effects of chitosan pentamer and chitosan hexamer in vivo and in vitro on gene expression and secretion of cytokines. Food Agric Immunol 20: 269-280.

Xia Z, Triffitt JT (2006) A review on macrophage responses to biomaterials. Biomed Mater 1: 1-9.

Yussof SJM, Halim AS, Saad AZM, Jaafar H (2011) Evaluation of the biocompatibility of a bilayer chitosan skin regenerating template, human skin allograft, and integra implants in rats. Mater Sci 2011: ID 857483.

\section{Discussion with Reviewers}

Reviewer I: How do results presented in this paper complement or explain in vivo data collected for inflammatory or host reactions to chitosan?

Authors: Our results, which indicate an anti-inflammatory polarisation of macrophages and moderate proinflammatory DC stimulation, may provide an explanation for the high biocompatibility of chitosan $(\mathrm{Ch})$ found in vivo in different tissues and for diverse applications. Although showing recruitment of inflammatory cells,
Ch was also demonstrated to induce low inflammatory reactions (Azab et al., 2007; Kim et al., 2011; VandeVord et al., 2002; Yussof et al., 2011). Even though some studies have documented exacerbated inflammatory reaction to Ch (Crompton et al., 2006; Hidaka et al., 1999; Peluso et al., 1994), it has also been shown that it is dependent on the degree of acetylation (DA) of the polymer (Barbosa et al., 2010; Hidaka et al., 1999; Tomihata and Ikada, 1997). In our case, the DA of the $\mathrm{Ch}$ used was below the range described to trigger severe inflammation (Hidaka et al., 1999) and Ch implants with the same DA did not induce any prolonged or exacerbated inflammatory responses throughout the implantation period (Yussof et al., 2011). Of note, most of the in vivo studies on the inflammatory reaction to $\mathrm{Ch}$ looked at number of recruited cells and their lineage and not at their activation or polarisation status (Barbosa et al., 2010; Crompton et al., 2006; Hidaka et al., 1999; Peluso et al., 1994; Tomihata and Ikada, 1997; Yussof et al., 2011). Finally, Ch has been reported as an adjuvant in immunotherapies (Muzzarelli, 2010).

Reviewer I: What is the in vivo evidence that DCs (distinct from macrophages) actually elicit and are involved in biomaterial-based (and specifically chitosan) inflammatory modulation?

Authors: The presence of dendritic cells at the implant site in vivo has been demonstrated using PLGA scaffolds, either in the presence or absence of an antigen (reviewed in Babensee, 2008). As for Ch in particular, it has also been demonstrated in vivo that orally administered $\mathrm{Ch}$ is taken by DC to the draining lymph nodes, in the case of Peyer's patches (Porporatto et al., 2005), and to enhance tolerance to an articular antigen (type II collagen) with a decrease in the inflammatory responses (Porporatto et al., 2009).

Reviewer I: The work by Leon et al. (2005) describes general evidence of in vitro/in vivo monocyte to $\mathrm{DC}$ differentiation, but does not provide any proof of DC involvement in a chitosan foreign body response. What is known about cellular components of foreign body response to chitosan implants?

Authors: To the best of our knowledge no study has investigated or identified yet the presence of DC in Ch scaffolds. However, DC recruitment to the implant site and interaction with PLGA scaffolds after $7 \mathrm{~d}$ postimplantation have been reported (Babensee, 2008). As for the cellular components of foreign body response to Ch implants, VandeVord and co-workers noted a dramatic infiltration of neutrophils, which were not activated, and that resolved with increasing implantation time (VandeVord et al., 2002). Four weeks post-implantation, a population with fibroblastic morphology was noticed. At later implantation stages, a variety of cells were observed within the Ch scaffold, including monocytes, macrophages, and giant cells, although the vast majority appeared to be fibroblasts (VandeVord et al., 2002). Similarly, Peluso et al. (1994) also reported the presence of many leukocytes at the polymer-tissue interface $14 \mathrm{~d}$ post-implantation. In addition, a mild foreign body response to $\mathrm{Ch}$, in comparison with absorbable surgical sutures (Azab et al., 2007), and to Gore-Tex and Vicryl (Kim et al., 2011) has been 
reported. Azab and co-workers found polymorphonuclear cells surrounding the implant at day 1 post-implantation, occasional macrophages at day 3 , and a decrease of the inflammatory infiltrate by day 14 (Azab et al., 2007). Finally, no adverse foreign body reaction to a $\mathrm{Ch}$ bilayer as compared to two commercially available skin substitutes was found, with the Ch group showing only low levels of acute inflammatory cells (Yussof et al., 2011).

Reviewer II: What is the mechanism or how could this different response to chitosan be explained.

Authors: The response of macrophages and DC to $\mathrm{Ch}$ is different but shows converging aspects, namely the production of TGF- $\beta$ and the lack of T cell stimulation. DC display a more pro-inflammatory phenotype than macrophages, yet their response does not correspond to a full-blown inflammatory reaction. For example, an increase of the co-stimulatory molecule CD86 is not accompanied by increasing expression of the activation marker CD83 or MHC-class II (HLA-DR), and there is no significant T cell stimulation. Also, in terms of cytokines, although we observe increased production of pro-inflammatory TNF- $\alpha$ and IL- $1 \beta$ combined with a reduction of anti-inflammatory IL-10, we do not see increased IL-12, a major hallmark of inflammation. We also observe an increase of TGF- $\beta$. Thus, we believe that in the presence of $\mathrm{Ch}$ alone, both macrophages and DC are likely to contribute to a proregenerative environment.

\section{Additional Reference}

Muzzarelli RA (2010) Chitins and chitosans as immunoadjuvants and non-allergenic drug carriers. Mar Drugs 8: 292-312. 